\title{
Cardiorenal syndrome: long road between kidney and heart
}

\author{
Carolina Victoria Cruz Junho ${ }^{1}$ Mayra Trentin-Sonoda ${ }^{2} \cdot$ Karine Panico $^{1,3} \cdot$ Raquel Silva Neres dos Santos $^{1}$. \\ Mariana Vieira Abrahão ${ }^{1}$. Imara Caridad Stable Vernier ${ }^{1}$. Cristina Ribas Fürstenau ${ }^{4}$. \\ Marcela Sorelli Carneiro-Ramos ${ }^{1}$ (1)
}

Accepted: 24 January 2022 / Published online: 8 February 2022

(c) The Author(s), under exclusive licence to Springer Science+Business Media, LLC, part of Springer Nature 2022

\begin{abstract}
Almost 200 years ago, the first evidence described by Robert Bright (1836) showed the strong interaction between the kidneys and heart and, since then, the scientific community has dedicated itself to better understanding the mechanisms involved in the kidney-heart relationship, known in recent decades as cardiorenal syndrome (CRS). This syndrome includes a wide clinical variety that affects the kidneys and heart, in an acute or chronic manner. Moreover, it is well established in the literature that the immune system, the sympathetic nervous system, the renin-angiotensin-aldosterone, and the oxidative stress actively play a strong role in the cellular and molecular processes present in CRS. More recently, uremic molecules and epigenetic factors have been also shown to be key mediators in the development of syndrome. The present review intends to present the state of the art regarding CRS and to show the paths known, until now, in the long road between the kidneys and heart.
\end{abstract}

Keywords Cardiorenal syndrome $\cdot$ Renal diseases $\cdot$ Cardiovascular diseases $\cdot$ Inflammation $\cdot$ Immune system

\begin{tabular}{|c|c|c|c|c|}
\hline \multicolumn{3}{|c|}{ Abbreviations } & ATP & Triphosphate adenosine \\
\hline \multicolumn{2}{|c|}{$\mathrm{ACE}$} & Angiotensin-converting enzyme & $\beta$-ARs & $\beta$-Adrenergic receptors \\
\hline \multicolumn{2}{|c|}{ ACEIs } & $\begin{array}{l}\text { Angiotensin-converting enzyme } \\
\text { inhibitors }\end{array}$ & CaMKII & $\begin{array}{l}\mathrm{Ca} 2+/ \text { calmodulin-dependent protein } \\
\text { kinase II }\end{array}$ \\
\hline \multicolumn{2}{|c|}{$\mathrm{ADHF}$} & Acute decompensated heart failure & CAT & Catalase \\
\hline \multicolumn{2}{|c|}{ AKI } & Acute kidney injury & CCL & (C-C motif) ligand \\
\hline \multicolumn{2}{|c|}{ Ang } & Angiotensin & CCR & $(\mathrm{C}-\mathrm{C})$ chemokine receptor \\
\hline \multicolumn{2}{|c|}{ ANS } & Autonomic nervous system & $\mathrm{CH}$ & Cardiac hypertrophy \\
\hline \multicolumn{2}{|c|}{$\mathrm{ARB}$} & Angiotensin receptor blockers & CKD & Chronic kidney disease \\
\hline \multicolumn{2}{|c|}{ ASC } & Apoptosis-associated speck & CRP & C-reactive-protein \\
\hline \multicolumn{2}{|c|}{ AT1 } & Angiotensin II type 1 receptor & CRS & Cardiorenal syndrome \\
\hline \multicolumn{2}{|c|}{ AT2 } & Angiotensin II type 2 receptor & CVD & Cardiovascular disease \\
\hline & & & CXCL & CXC chemokine ligands \\
\hline \multirow{3}{*}{$凶$} & \multirow{3}{*}{\multicolumn{2}{|c|}{$\begin{array}{l}\text { Marcela Sorelli Carneiro-Ramos } \\
\text { marcela.ramos@ufabc.edu.br; msorelli@gmail.com }\end{array}$}} & DAMPs & Damage-associated molecular patterns \\
\hline & & & DCs & Dendritic cells \\
\hline & & & DRI & Direct renin inhibitors \\
\hline \multirow[t]{3}{*}{1} & \multirow{3}{*}{\multicolumn{2}{|c|}{$\begin{array}{l}\text { Laboratory of Cardiovascular Immunology, Center } \\
\text { of Natural and Human Sciences (CCNH), Federal University } \\
\text { of ABC, Santo Andre, SP, Brazil }\end{array}$}} & $\mathrm{EC}$ & Endothelial cell \\
\hline & & & eNOS & Endothelial NOS \\
\hline & & & ESKD & End-stage kidney disease \\
\hline \multirow[t]{3}{*}{2} & \multirow{2}{*}{\multicolumn{2}{|c|}{$\begin{array}{l}\text { Division of Nephrology, Department of Medicine, Kidney } \\
\text { Research Centre, Ottawa Hospital Research Institute, } \\
\text { University of Ottawa, Ottawa, ON, Canada }\end{array}$}} & ERK & Extracellular signal-regulated kinases \\
\hline & & & $\mathrm{EVs}$ & Extracellular vesicles \\
\hline & \multirow{3}{*}{\multicolumn{2}{|c|}{$\begin{array}{l}\text { Laboratory of Cellular Biology and Functional Anatomy, } \\
\text { Institute of Biomedical Sciences (ICB III), University of São } \\
\text { Paulo, Sao Paulo, SP, Brazil }\end{array}$}} & FGF23 & Fibroblast growth factor 23 \\
\hline \multirow{2}{*}{3} & & & GFR & Glomerular filtration rate \\
\hline & & & HMGB1 & High mobility group box 1 \\
\hline \multirow[t]{2}{*}{4} & \multirow{2}{*}{\multicolumn{2}{|c|}{$\begin{array}{l}\text { Laboratory of Vascular Biochemistry, Center of Natural } \\
\text { and Human Sciences (CCNH), Federal University of ABC, } \\
\text { Santo Andre SP Brazil }\end{array}$}} & $\mathrm{HF}$ & Heart failure \\
\hline & & & $\mathrm{HOCl}$ & Hypochlorous acid \\
\hline
\end{tabular}




\begin{tabular}{|c|c|}
\hline HSPS & Heatshock proteins \\
\hline ICAM-1 & Intercellular adhesion molecule 1 \\
\hline IFM & Interfibrillar mitochondria \\
\hline IFN & Interferon \\
\hline IL & Interleukin \\
\hline IRI & Ischemia and reperfusion injury \\
\hline IS & Indoxyl sulfate \\
\hline LV & Left ventricle \\
\hline MAPK & Mitogen-activated protein kinase \\
\hline MBD & Mineral bone disorder \\
\hline MC & Mast cell \\
\hline MCO & Medium cut-off \\
\hline MDA & Malondialdehyde \\
\hline MHC & Major histocompatibility complex \\
\hline MI & Myocardial infarction \\
\hline MiR or MiRNA & MicroRNA \\
\hline MMPs & Matrix metalloproteases \\
\hline MPs & Mononuclear phagocytes \\
\hline $\mathrm{NF}-\kappa \mathrm{B}$ & Nuclear factor kappa B \\
\hline $\mathrm{Nfr} 2$ & Nuclear factor erythroid 2 \\
\hline NLR & NOD-type intracytoplasmic receptor \\
\hline NO & Nitric oxide \\
\hline NOS & Nitric oxide synthase \\
\hline NOX & NADPH oxidase \\
\hline PAMPs & Pathogen-associated molecular patterns \\
\hline PBUT & Protein-bound uremic toxin \\
\hline PCS & P-Cresyl sulfate \\
\hline PMNs & Polymorphonuclear neutrophils \\
\hline PRA & Plasma renin activity \\
\hline PTH & Parathyroid hormone \\
\hline RAAS & Renin-angiotensin-aldosterone system \\
\hline ROS & Reactive oxygen species \\
\hline RNS & Reactive nitrogen species \\
\hline SOCS & Suppressor of cytokine signaling \\
\hline SOD & Superoxide dismutase \\
\hline SNS & Sympathetic nervous system \\
\hline TAC & Transversal aortic constriction \\
\hline TGF- $\beta$ & Transforming growth factor beta \\
\hline TLR & Toll-like receptors \\
\hline TNF- $\alpha$ & Tumor necrosis factor-alpha \\
\hline Tregs & Regulatory T cells \\
\hline UT & Uremic toxins \\
\hline VCAM1 & Vascular cell adhesion protein 1 \\
\hline VSMC & Vascular smooth muscle cells \\
\hline
\end{tabular}

\section{Cardiorenal syndrome: general considerations}

The relationship between the heart and kidneys has been studied since 1836, starting with the connection between proteinuria and cardiac alterations [1]. The first study concerning this subject was published by Robert Bright (1836), who observed that the prevalence of cardiovascular diseases (CVD) in patients with renal disease was accompanied by the secretion of urinary albumin [1]. Although the connection between the two organs has been studied for almost two centuries, it was only in 2004 that the National Heart, Lung, and Blood Institute formally attempted to define cardiorenal syndrome (CRS) as an increase in systemic volume by the kidneys that is aggravated by the progression of heart failure (HF). In 2008, the definition of CRS became considerably broader when the Acute Dialysis Quality Initiative reached a consensus of two major CRS groups, cardiorenal and reno-cardiac, based on the initial pathology, and then further subdivided into five types of CRS [2,3]. The results are summarized in Table 1.

It is notable that all CRS types have crosstalk, and all can develop into a cycle that worsens both the primary and secondary conditions, further aggravating the pathology shown in Fig. 1 and Table 1. In general, patients with CRS usually exhibit systemic congestion (45\% of patients, and for those who present, $80 \%$ of cases present with severe congestion), hyperkalemia, hypertension, elevation of creatinine $(<30 \%$ in relation to baseline), and resistance to diuretics and others [3]. It is important to observe that all CRSs share the same mechanisms to maintain (or attempt to maintain) homeostasis. These are the renin-angiotensin-aldosterone system (RAAS), sympathetic nervous system (SNS), inflammation, and oxidative stress. The first are principal mechanisms of regulation with respect to volume and pressure to stabilize CRS; therefore, these are the main targets of pharmacological treatments.

Different studies have shown distinct alterations in response to CRS, such as the loss of renal blood flow selfregulation, abnormalities in renovascular reactivity, intermittent activation of renin-angiotensin (increasing angiotensin II type 1, AT1 and AT2), and sympathetic systems, decreasing aorta responsivity, uremia, and metabolic acidosis. All of these changes elicit endothelial dysfunction that is detected by the loss of endothelial sensitivity to acetylcholine [15-18]. Direct damage to the endothelium is also recognized by the immediate inhibition of endothelial nitric oxide synthase (eNOS), leading to the known vasoconstrictor profile of inflamed arteries and an increase of inflammatory cytokines, such as tumor necrosis factor-alpha (TNF- $\alpha$ ), IL- (interleukin) 1, and IL-6 in the renovasculature [19]. Additionally, Casas et al. detected a pro-inflammatory environment due to an increase in C-reactive protein, fibrinogen, and IL-1 $\beta$ markers in the blood of patients with chronic renal dysfunction and consequent coronary disease [20].

Although vascular effects of CRS mainly concern the renovasculature, many authors have also investigated vascular alterations in distinct models of renal failure in other vascular beds. In 1981, Ueda et al. showed that aortas from attached ureter rats were less responsive to norepinephrine 


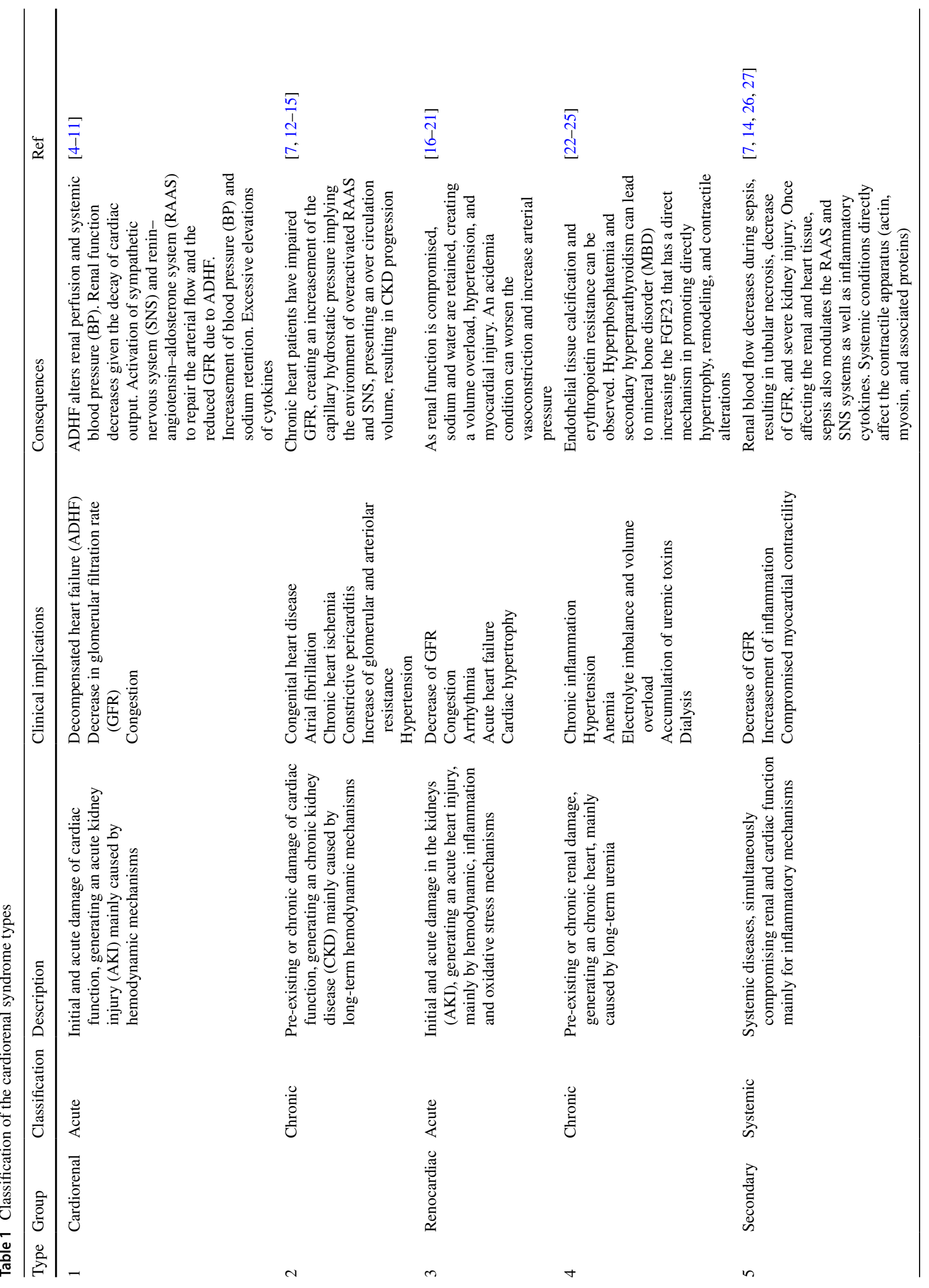




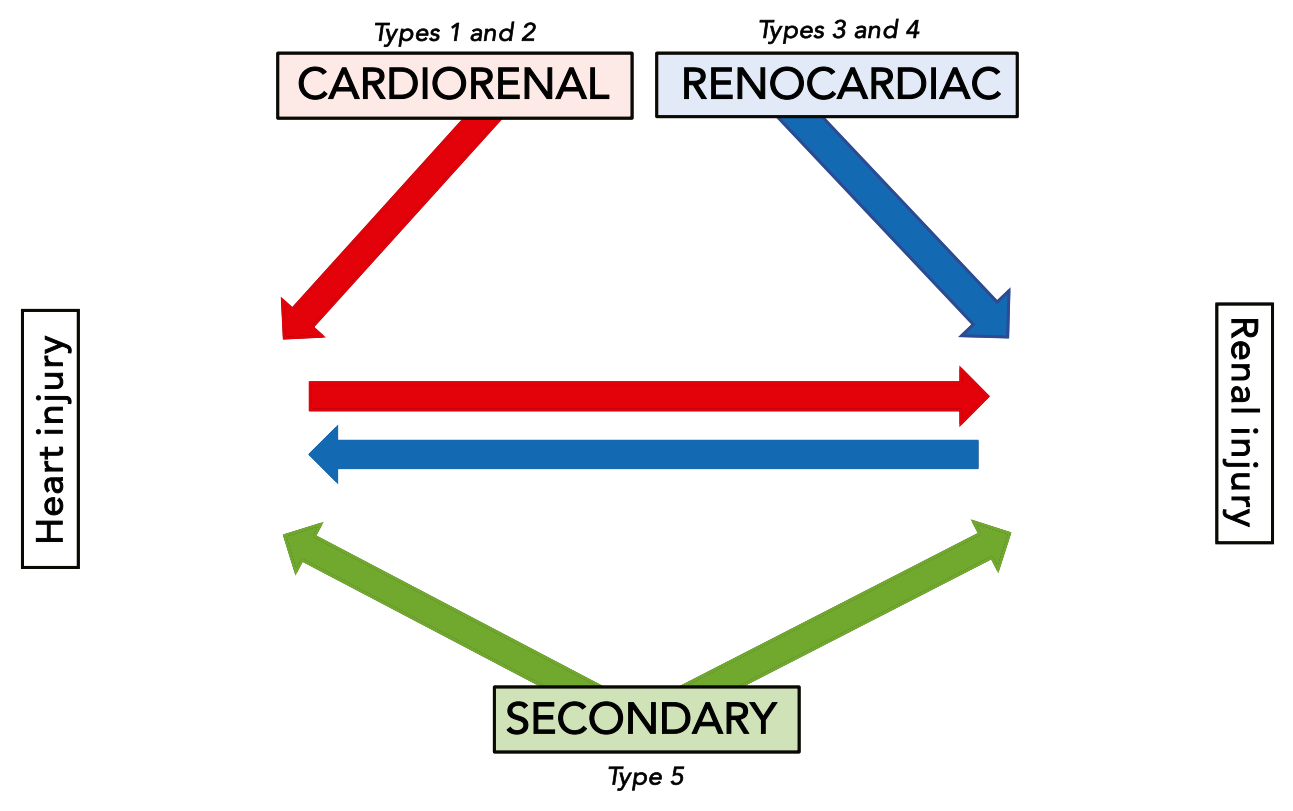

Fig. 1 Flowchart describing the sequence of organ involvement during the five types of cardiorenal syndrome (CRS). The red arrows indicate CRS types 1 and 2, which are considered cardiorenal; the first injury occurs in the heart as acute decompensated heart failure (ADHF) which is type 1 and chronic heart failure (CHF) which is type 2. The blue arrows indicate CRS types 3 and 4, which are considered renocardiac; the first injury occurs in the kidneys as AKI which is type 3 and CKD which is type 4 . The green arrows indicate CRS type 5 which is considered secondary; when a secondary dis-

and angiotensin II (Ang II) in comparison to control animals, although no significant histological lesions were observed [21]. Using a model of renal failure due to subtotal nephrectomy, Amann et al. reported an increase in aortic wall thickness provoked by secretion of factors stimulating proliferation of vascular smooth muscle cells. This resulted in an increased matrix deposition [22]. In a 5/6 nephrectomy rat model, Nesher et al. showed a reduction of the aortic contraction in response to $\mathrm{KCl}$, while acetylcholine vasodilation was impaired in animals with chronic renal failure. Such effects were prevented by administration of L-arginine in the rats' drinking water [23].

\section{The vehicles traveling along the highway: classical cellular mechanisms in CRS}

\section{RAAS in CRS}

One of the most impressive systems in the control of cardiovascular function is RAAS. Until the 1980s, only Ang II was studied as an active peptide of this system. It was produced by an enzymatic cascade from the action of renin on its angiotensinogen substrate and then by the action of the angiotensin-converting enzyme (ACE) (Fig. 2). Until then, ease such as sepsis or diabetes impairs the heart and kidney function concomitantly, the primary and secondary injuries occur due to the systemic disease, that simultaneously induces both cardiac and renal dysfunction, as if it were bi-directional. The physiological disturbances shared by all CRS types are imbalance of hemodynamics (increase of sodium and water retention), congestion, inflammation, oxidative stress, activation of renin-angiotensin-aldosterone (RAAS), and sympathetic nervous system (SNS)

this vasopeptide acted through the AT1 receptor, promoting vasoconstriction, water intake, and $\mathrm{Na}^{+}$retention. In the early 1990s, new components of this system were discovered through an independent ACE pathway [24]. These components formed from angiotensin (Ang) I and are referred to as Ang 1-7. Pharmacological blockade of RAAS occurs through the inhibition of ACE or angiotensin receptor blockers (ARB) and has been used widely in the control of renal and cardiac injury, such as chronic kidney disease (CKD) and $\mathrm{HF}[25,26]$.

It is well known that increased Ang II levels in the heart can lead to myocardial necrosis [90], whereas RAAS stimulation can cause coronary cell death due to intense coronary vasoconstriction [91-93]. It is also known that high levels of Ang II act through several physiological mechanisms, resulting in myocardial damage (e.g., apoptosis of coronary endothelial cells (EC) or cardiac myocytes).

Several studies have reported increased cardiac expression of AT1 over the course of cardiac development and the progression of cardiac failure after myocardial infarction (MI) and other cardiac diseases [27-29], demonstrating that the increase in AT1 expression mediates the hypertrophic role of Ang II [30-32]. Considering these results, the RAAS blockade prevents excessive sodium reabsorption and adverse cardiac remodeling, as well as 
Fig. 2 Flowchart describing the action of the renin-angiotensinaldosterone system (RAAS) in CRS. Activation of the RAAS system occurs after renin release in the kidneys that catalyzes the synthesis of angiotensinogen to form angiotensin I (Ang I). Ang I is converted to Ang II by ACE produced in the lungs. Ang II binds to AT1 receptors in the smooth muscle cells of the peripheral blood vessels causing vasoconstriction and increasing vascular resistance and blood pressure in the heart. It can also cause hypertrophy, fibrosis, and heart failure (HF). In the figure, it is possible to see the therapies involved in the RAAS blockage: AT1 antagonists, ACR blockers, and renin inhibitors

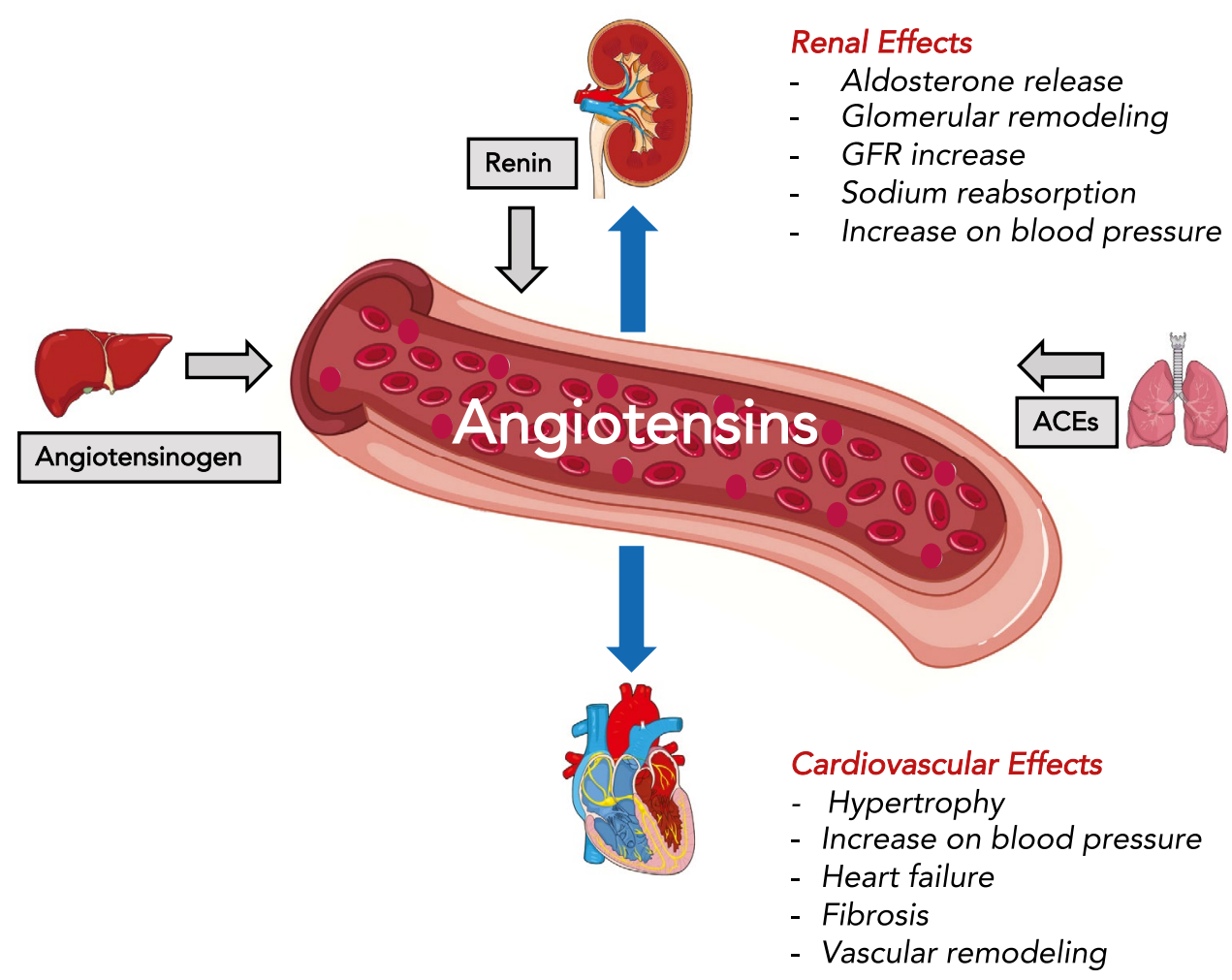

myocardial ischemia and reperfusion injury (IRI) lesions and post-infarction remodeling [33, 34]. Recent studies on pharmacological approaches are discussed further.

Panico et al. demonstrated that the pharmacological manipulation of RAAS suggests that Ang II formation is also important in attenuating CRS in mice after renal IRI [35]. In the same study, the authors showed that acute kidney injury (AKI) induced by unilateral IRI did not change plasma levels of Ang II, but cardiac RAAS seemed to be important in avoiding the worsening observed in this model [35]. The beneficial effects of Ang II may be related to vasoconstrictor effects, which decrease the inflow of inflammatory mediators and maintain endothelial nitric oxide (NO) levels in the renal tissue. Furthermore, cardiac Ang II could stimulate the ACE2/Ang 1-7/ MAS receptor axis, which is responsible for inflammation during renoprotection [36-38].

Despite the described and known benefits of RAAS blockade in the isolated heart or kidney and its cardioprotective and renoprotective effects, the role of this system and its implications in cardiorenal patients requires further examination. Recently, worldwide researchers have focused their attention on the regulatory axis of SARSCoV-2, which highlights the protective action of ACE2/ Ang 1-7 on the cardiovascular system [39-41].

\section{Neurohumoral control in CRS}

The autonomic system (ANS) plays an important role in several biological processes, from behaviors and emotions to immune system functions [42]. It operates through catecholamines, epinephrine, and noradrenaline. These chemicals belong to large families of $\alpha$-and $\beta$-adrenergic receptors (adrenoceptors, $\beta$-ARs) that are distributed in different tissues, with the most varied levels of expression performing similar functions in the pathway activation that modulates calcium transport for muscle contraction [43].

The ANS is fundamental to BP control, whether continuously (long-term) or moment-to-moment. These adjustments are responsible for hemodynamic stability. Thus, we can highlight a study in patients with end-stage kidney disease (ESKD) that had an increased risk of CVD and sudden death with increased SNS activity [44].

Renal IRI leads to the development of cardiac hypertrophy $(\mathrm{CH})$. In many other models, AKI can directly or indirectly induce acute cardiac dysfunction by increasing angiotensin levels (AT1, AT2, and ACE), local and systemic cytokines (TNF- $\alpha$, ILs, and IFN- $\gamma$ ), arrhythmias, and other components $[45,46]$, such as increasing the presence of local norepinephrine and increasing sympathetic activity [35, 47]. 
Some vasomotor sympathetic activity is a common characteristic of HF [48]. Therefore, the SNS is a relevant therapeutic target [47]. During HF, renal sympathetic nerve activity increases and causes renal norepinephrine accumulation and renin release, which induces renal vasoconstriction that may contribute to CRS. Additionally, RAAS is induced, which interrupts the balance between reactive oxygen species (ROS), NO, and inflammation. In combination with decreased renal perfusion and increased pressure of the renal vein, these factors contribute to the pathogenesis of CRS [48].

A study of myocardial infarction (MI) induced by thoracic aortic coarctaction (TAC) demonstrated an increase in norepinephrine levels in the plasma and urine, which was reduced with concomitant renal denervation. This treatment showed an improvement in renal injury induced by aortic regurgitation and decreased expression levels of KLF5, S100A8, S100A9, TNF, CSF2, and Ly6Clo macrophages. There was also a decrease in left ventricle (LV) systolic function, $\mathrm{CH}$, fibrosis, and survival after infarction, indicating the importance of sympathetic activity in the kidneys and heart. Additionally, renal denervation was performed. Inhibition of cardiac afferent nerve signaling through the administration of epicardial capsaicin and/or resection of the spinal dorsal horn, which also reduced the expression of CSF2 in the kidneys after thoracic aortic coarctation, indicates that cardiac afferent nerves have an intrinsic interaction between the heart and the brain [49].

Among the conditions that raise the hemodynamic levels for both the heart and kidneys, we highlight inflammatory factors (Fig. 3). An important role for IL-6 is documented in the mechanisms involved in the development of $\mathrm{CH}$ [50], which precedes HF. This is a process that also involves the presence of the SNS, where catecholamines that are present in the immune cells can play a crucial role in the SNS interface and immune system [51]. An association between changes in levels of Ang II and cytokines, with increased cardiac mass and cardiac remodeling, increases SNS activity in the heart [52-54].

Gueguen et al. and Vieira-Rocha et al. demonstrated the role of the RAAS and SNS in the pathogenesis of hypertension in different models of hypertension, comparing BPH/2 J (hypertensive) and BPN/3 J (normotensive) mice and neuromodulation of the vascular angiotensin AT1 in fetal programming of hypertension, respectively. The elevated renal levels of norepinephrine contributed to the evolution of hypertension via expression of renin or the occurrence of hypersympathetic activation. This activation involved tonic facilitation, through endogenous Ang II, of pre-junctional AT1 receptors, resulting in the development of hypertension in these animals $[55,56]$.

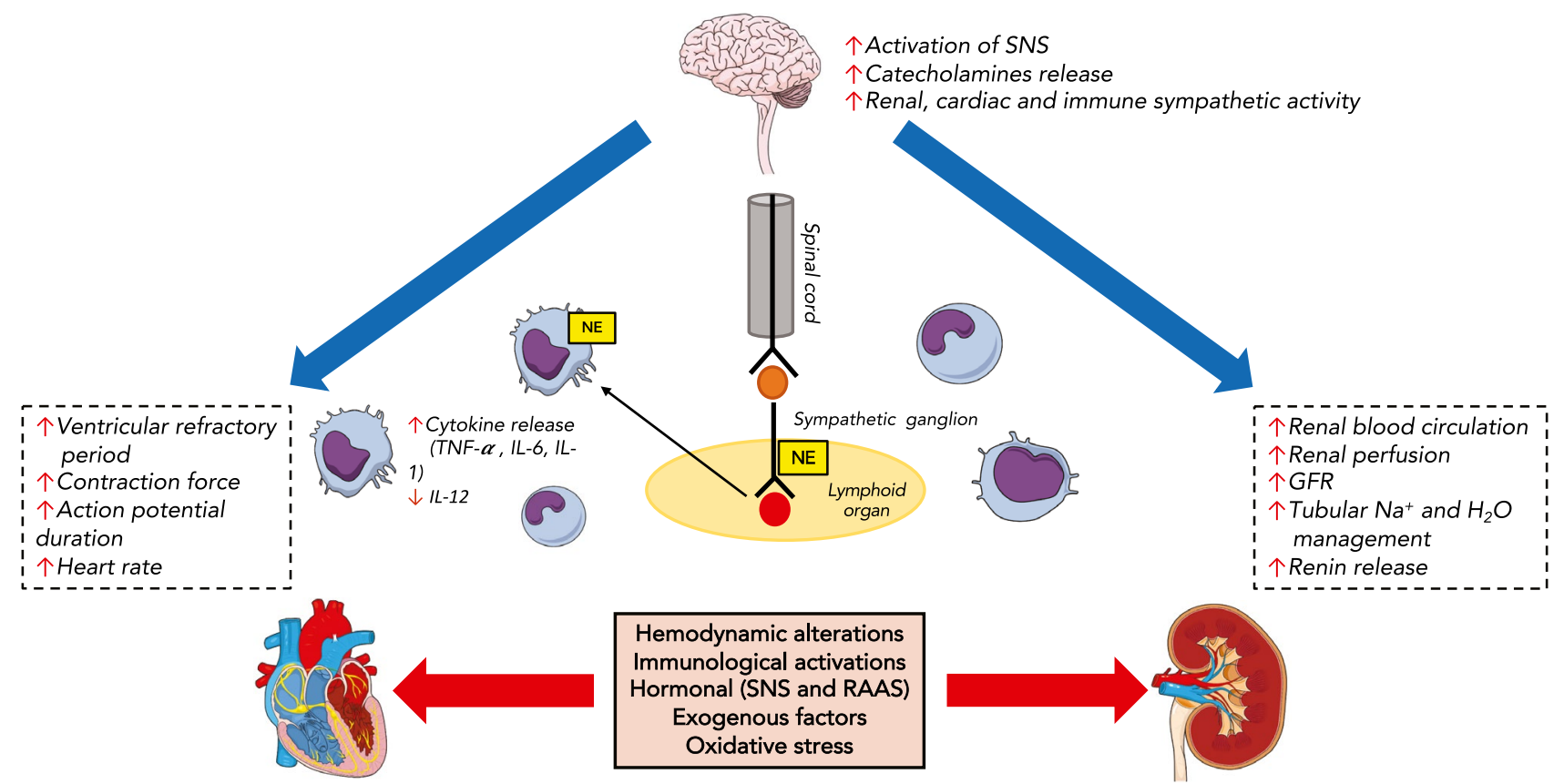

Fig. 3 Flowchart describing the action of the neuronal control of the sympathetic nervous system (SNS) in CRS. The SNS acts through the catecholamines, noradrenaline, and epinephrine. This system has direct interference in the immune system, and is the main connec- tor between the heart-kidney axis, promoting the movement of the involved immune cells from the kidney that reach the heart through the bloodstream (cytokines: IL-1, TNF- $\alpha$, IL-6), leading to both cardiac and renal dysfunction 
The development and progression of CRS occurs through feedback activation of neurohormonal pathways. Both $\beta$-adrenergic blockade and inhibition of RAAS, among other methods, can act as new therapeutic strategies to mitigate the deleterious processes linked to HF and CRS. This will be discussed further in the following sections.

\section{Inflammation in CRS}

During the inflammatory phase, immune cells, such as mature phagocytes, are recruited to the infarcted area to clean the dead cells and matrix debris. The elimination of dead cells and matrix debris stimulates anti-inflammatory pathways and targets the transition to the proliferative phase, accompanied by immune cell infiltration, activated fibroblasts, and an increase in angiogenic processes. Concomitantly, toll-like receptors (TLRs) are activated in response to damage-associated molecular patterns (DAMPs) or pathogen-associated molecular patterns (PAMPs) present in many cell types, including resident cardiac macrophages, fibroblasts, cardiomyocytes, mast cells (MCs), vascular cells, and infiltrating leukocytes $[57,58]$. Both the innate and adaptive immune responses are induced by TLR stimulation [59]. In Fig. 4, we observed the activation of signaling pathways in white cells (mainly macrophages). Two signals are activated by CRS DAMP during stress. (1) The first is through the classical TLR2/4 pathway that releases IL- $1 \beta$. This cytokine is fundamental to the maintenance of cardiac alterations during CRS type 3, for example, (2) NLRP3 signaling. This signal begins with the phagocytosis of DAMP,

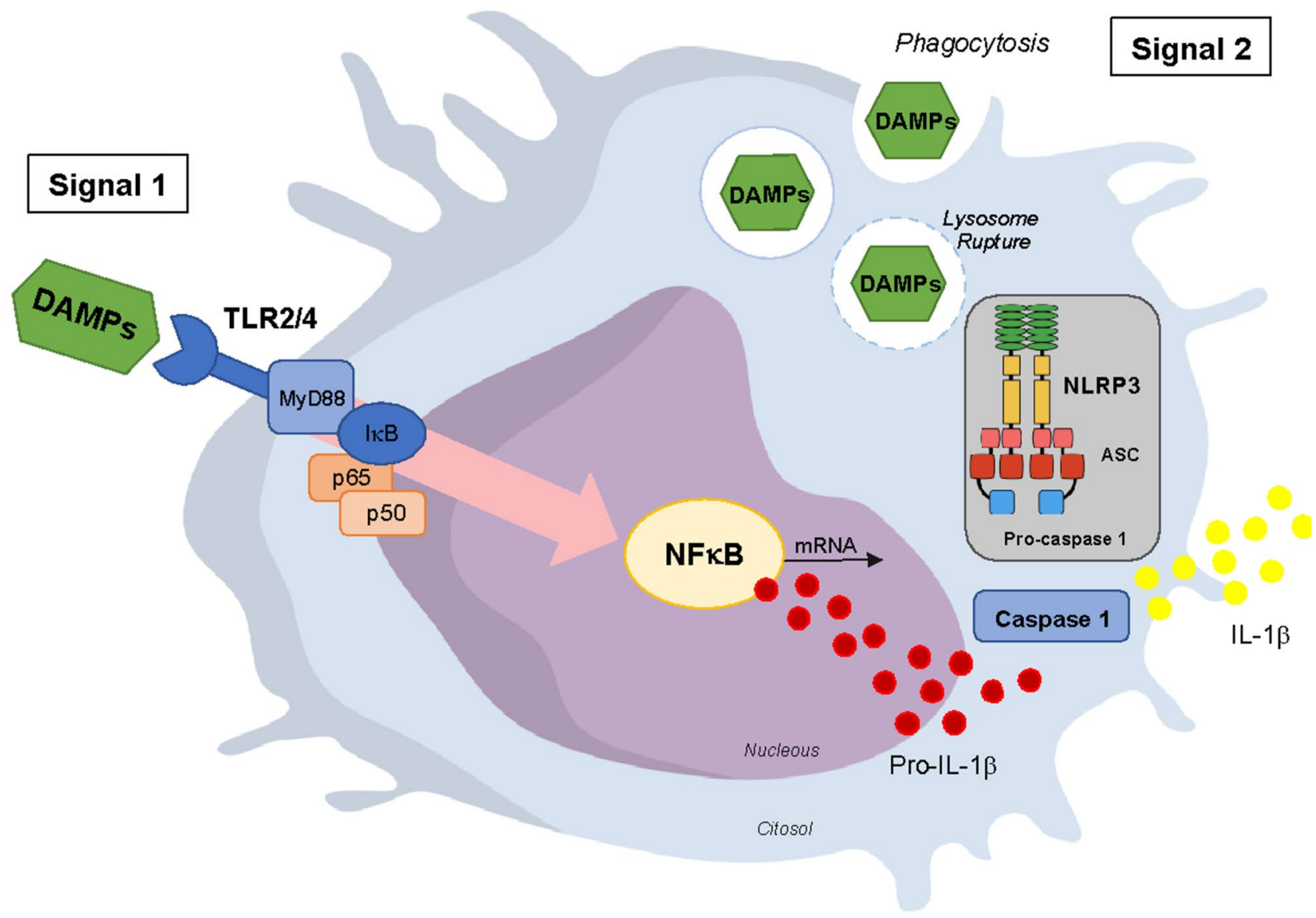

Fig. 4 Principal mechanisms evoked by damage-associated molecular patterns (DAMPs) during CRS. Two signals are activated by DAMPs during the CRS. The DAMPs can be inflammatory factors, oxidative stress components, uremic toxins accumulated during renal failure, sepsis, and diabetes. Signal 1: the classical TLR2/4 pathway. When connected with the receptor, the DAMPs promote the activation of MyD88 and the release of the transcription factor, NF-kB, that synthetizes pro-inflammatory mRNA expression, like the pro-IL-1 $\beta$. When activated, this cytokine is fundamental to the maintenance of cardiac alterations during CRS. Signal 2: the NLRP3 signal. This signal starts by the phagocytosis of the DAMP, activating the signal though lysosomal damage. Activation of the NOD-type intracytoplasmic receptor (NLR) family can lead to the formation of protein complexes called inflammasomes, including the NLRP3 inflammasome, formed by three basic structures: NOD-type receptors, adapter protein (ASC), and pro-caspase 1 . These active caspases are capable of inducing proteolytic maturation of interleukin-1 beta (IL-1 $\beta$ ), which are then released into the extracellular environment stimulating other cells such as the cardiomyocytes and podocytes 
activating the signal through lysosomal damage. Activation of the NOD-type intracytoplasmic receptor (NLR) family can lead to the formation of protein complexes called inflammasomes, including the NLRP3 inflammasome. NLRP3 is formed by three basic structures: NOD-type receptors, adapter protein (ASC), and pro-caspase 1. These active caspases are capable of inducing proteolytic maturation of IL- $1 \beta$ and IL-18, which are released into the extracellular environment and stimulate other cells, such as cardiomyocytes and podocytes [60]. Both signaling pathways were studied in renal IRI and diabetic mice, respectively, and in both models, signal 2 showed great importance for the maintenance of cardiac alterations and was shown to be a potential therapy for CRS [46, 61].

In the HF setting, there is increased expression of TLR4 in the cardiac myocytes of both humans and rodents. In the heart, TLR signaling stimulates two downstream pathways. In the acute phase of ischemia, it is cytoprotective and may increase the function of cardiac myocytes. In contrast, chronic activation of TLRs (TLR4 and TLR2) leads to left ventricular dysfunction [59]. The leukocyte-specific activation of TLR2- or complement-mediated signaling in bone marrow transplantation experiments was associated with marked injury after infarction, suggesting that innate immune activation may extend ischemic injury [57]. Another role for innate immunity in HF is the process by which apoptotic polymorphonuclear neutrophils (PMNs) attract macrophages to the site of injury to limit neutrophil activity. If PMN infiltration remains unmarked or if there is a prolonged persistence of inflammatory triggers at the site of injury, a negative feedback loop is created, inducing chronic inflammation that does not resolve [62].

Under conditions of myocardial ischemia in experimental mouse models, myocardial cells undergo necrosis, thus releasing DAMPs, such as triphosphate adenosine (ATP) and high mobility group box 1 (HMGB1). These DAMPs culminate with the release of cytokines such as IL-1 $\beta$, IL-18, and TNF- $\alpha$ by cardiac resident cells, in turn activating ECs. In this scenario, the uptake of cell debris by cardiac macrophages induces a type I interferon (IFN) response that initiates inflammation post-MI. After ischemia (within 12-24 h post-MI), neutrophils are the first inflammatory cells recruited through the chemoattractant chemokine (C-X-C motif) ligands (CXCL) 1, CXCL2, and CXCL8. Neutrophils produce IL-6, which activates ECs and induces the $\mathrm{C}-\mathrm{C}$ motif ligand (CCL) and vascular cell adhesion protein 1 (VCAM1) for subsequent monocyte recruitment. They also release matrix metalloproteases (MMPs) to break down the extracellular matrix and dead cells within the infarcted area. Splenic Ly6C ${ }^{\text {hi }} \mathrm{CCR} 2{ }^{\text {hi }} \mathrm{CX} 3 \mathrm{CR} 1{ }^{\text {lo }} \mathrm{CD} 62 \mathrm{~L}^{+}$monocytes are recruited via $\mathrm{C}-\mathrm{C}$ motif chemokine ligand 2 (CCL2) chemokine receptor (CCR) 2 chemoattraction. These cells scavenge debris and release inflammatory cytokines and MMPs at the infarct site. Thus, the inhibition of the CCL2-CCR2 pathway has been effective in avoiding monocyte recruitment, improving infarct healing, and attenuating LV remodeling post-MI [63, 64].

On the other hand, inflammatory cytokines such as IL-4, IL-6, and TNF- $\alpha$ are important agents that promote $\mathrm{CH}$, fibrosis, and dysfunction, as evidenced in anterior studies using a pressure overload experimental model. Increased myocardial expression of TNF- $\alpha$, IL- $1 \beta$, and IL- 6 was observed in patients with pressure overload [65]. In cardiac fibroblasts, increased production of these three cytokines has been associated with reduced collagen synthesis and infarct expansion [66]. In pressure overload-induced HF, innate immune cells, including monocytes, mononuclear phagocytes (MPs), dendritic cells (DCs), and macrophages provide an inflammatory response by delivering proteases and cytokines. Additionally, macrophages promote efferocytosis and phagocytosis, and activate myofibroblasts and immune cells, indicating that MPs participate in pressure overload-induced HF [65]. At the same time, activation of the nuclear factor kappa B (NF-kB) signaling pathway, an important regulator of cellular inflammation that is related to an increase in renal expression of IL- 6 and TNF- $\alpha$, causes a decrease in renal function [4].

DCs are another example of immune cell involvement in CRS and may be involved in the connection between heart and kidney diseases. Virzì et al. demonstrated in an Ang II-induced renal damage model, renal DCs expressed major histocompatibility complex (MHC) class II and CD86 (markers of DC maturation), causing $\mathrm{CD} 4+$ and $\mathrm{CD} 8+\mathrm{T}$ cells to infiltrate the kidney. This demonstrates the performance of DCs as connectors of innate and adaptive immunity [67]. Additionally, Bansal et al. reported on the role of DCs as antigen-presenting cells in T lymphocytes, inducing their activation.

Under the scenario of a reduced left ventricular ejection fraction and increased volume of the diastolic and final systolic areas in the LV, elevated circulating levels of these cytokines have been observed to have direct cardio-depressive effects. In renal ischemia, systemic inflammation and not AKI plays an immediate role in myocardial damage and dysfunction, as evidenced in rat hearts, where there is higher expression of ICAM-1 (intercellular adhesion molecule 1) and apoptosis in the myocardium. Additionally, $48 \mathrm{~h}$ after kidney injury, damage such as increased diastolic and systolic diameters at the end of the LV decreased fractional shortening, left ventricular dilation, and increased relaxation times were observed [68]. During the progression of HF in humans, increased circulating levels of TNF- $\alpha$ and IL-6 have been found, which are associated with increased mortality [69]. Castillo-Rodriguez et al. compared these inflammatory cytokines with uremic toxins (UTs), suggesting that their accumulation contributes to CKD 
manifestations and fulfills the criteria to be considered as UTs [69].

Another example is the generation of an early immune response consisting of the activation of DCs and the activation of signaling pathways dependent on IL-23/IL-17 and IL-12/IFN- $\gamma$. Due to kidney damage caused by IRI, neutrophils, macrophages, and lymphocytes (particularly $\mathrm{CD}^{+} \mathrm{T}$ cells and B cells) are elevated. The activation of antigen-dependent $\mathrm{T}$ cells has also been demonstrated in experimental models of renal IRI. T cells undergo early activation and become a bridge between the adaptive and innate immune systems after antigen activation or in the presence of chemokines. This specific immune response during AKI leads to a cardiorenal connection [8].

The activation of TLR 2 and TLR 4 followed by an increase in inflammatory cytokines, immunosuppressive cytokines, DCs, and T cell activation was observed in an acute myocardial ischemic injury renal IRI model, confirming that ischemia/reperfusion rapidly activates the innate immune response. In contrast, post-injury renal TNF- $\alpha$ levels were significantly reduced due to the depletion of DCs before IRI [67]. TLRs can also be activated by heat shock proteins (HSPs) that interact with both kidney cells and cardiomyocytes. This family of proteins are important mediators involved in the control of gene transcription and intracellular signaling, in addition to being important connectors of the immune system, mainly HSP60, 70, and 90 [70].

Higher levels of IL-18 expression lead to the production of IL-1 $\beta$, which has negative inotropic effects on the myocardium in both in vitro and in vivo models. Additionally, IL-18 induces cardiac fibrosis and hypertrophy. During AKI, elevated levels of TNF- $\alpha$ have been found to cause direct depressant effects on the myocardium by reducing the sensitivity of the $\beta$-ARs to catecholamines, altering calcium signaling, and inducing apoptosis. Inhibition of TNF- $\alpha$ led to decreased cardiac apoptosis in rat models. In experimental models, renal ischemia for $30 \mathrm{~min}$ led to abrupt increases in IL-1 and TNF- $\alpha$ levels in the systemic circulation, with concomitant detection in cardiac tissues. The increased expression of ICAM-1 in ECs and infiltration of leukocytes into the myocardium were accompanied by an increase in the cardiac activity of IL-1 and TNF- $\alpha$ [71].

In acute coronary syndrome, IL-6 may induce antiapoptotic pathways, thereby restricting tissue damage. On the other hand, sustained IL-6 levels might also lead to deleterious effects via reduced expression of suppressors of cytokine signaling (SOCS)-3 and increased neutrophilic recruitment. This cytokine, together with IL- $1 \beta$, stimulates $\mathrm{C}$-reactive protein (CRP) production. Overproduction of IL- $1 \beta$ has been shown to be due to AKI and is produced by ECs and macrophages in the coronary arteries in ischemic heart disease [71]. When using an IL-1 $\beta$ antagonist as treatment, the duration and amplitude of calcium transience were rescued, thus preventing ventricular arrhythmias [46].

\section{Oxidative stress in CRS}

ROS are produced at controlled and physiological levels that may exert beneficial cellular functions, such as a second messenger in cellular signaling pathways, cognitive function, yield of thyroid hormone, and participation in immunological responses [72]. However, excessive production of ROS or reactive nitrogen species (RNS) leads to detrimental effects, disrupting cellular homeostasis by damaging cellular proteins, lipids, and DNA, which results in dysfunction and cellular death $[73,74]$.

The generation of ROS and RNS occurs in the kidneys under physiological and pathological conditions, and the major sources of ROS in the kidneys are NADPH oxidase (NOX) 4 and [75, 76]. Through pathological stimuli, such as Ang II, TNF- $\alpha$, high glucose, and even superoxide anion $\left(\mathrm{O}_{2}{ }^{-}\right)$from NADPH oxidase, mitochondrial increases of $\mathrm{O}_{2}{ }^{-}$release and the complementary reduction of Mn-SOD worsens make the production of $\mathrm{O}_{2}{ }^{-}$, inducing oxidative stress $[77,78]$.

It is thought that the key role of oxidative stress in various types of AKI and CKD diseases both directly and indirectly affects all kidney hemodynamic functions, such as glomerular filtration, tubular reabsorption, and secretion, leading to cellular apoptosis, fibrosis, and impaired function. Meng et al. demonstrated that NOX4 overexpression in the toxic AKI model confirmed the significance of this overexpression by leading the kidneys to programmed cell death and inflammation. They highlighted its depletion as a potent therapeutic agent [79]. Other studies involving cisplatinAKI indicated increased lipid peroxidation and impaired antioxidant enzyme activity [80]. Choi et al. observed the same lipid peroxidation through malondialdehyde (MDA), which occurred simultaneously with apoptosis of renal tubule cells and inflammatory infiltration in an AKI model using Sprague-Dawley rats [80]. Other groups using a renal bilateral IRI model in Wistar rats showed the same increase in MDA levels [40].

During the progression of CKD, an alteration in nuclear factor erythroid 2 (Nfr2), which is responsible for encoding many enzymatic antioxidants, modulates activity of enzymatic antioxidants superoxide dismutase (SOD), enhances activity of NOX, and exhibits characteristics of carbonyl stress [81]. In CKD that results from diabetes and hypertension, it is well established that Ang II also enhances oxidative stress and inflammation. Similarly, so does the AT1 receptor, which stimulates NADPH oxidase and mitochondria to generate $\mathrm{O}_{2}{ }^{-}$, and reduces glutathione cycle activity by inhibiting Nrf2 [82, 83]. 
In healthy hearts, the generation of ROS and RNS comes from ECs, phagocytes, and cardiomyocytes. In cardiomyocytes, the peroxisomes, xanthine oxidase, and xanthine are the principal sources of $\mathrm{ROS} \mathrm{O}_{2}{ }^{-}$and $\mathrm{H}_{2} \mathrm{O}_{2}$, whereas NOS enzymes release NO. In ECs, only xanthine oxidase produces $\mathrm{O}_{2}{ }^{-}$, and NOS generates NO. In phagocytes, NOX and prostaglandin hydroperoxidases are involved in releasing $\mathrm{O}_{2}^{-}$, and when activated, these cells are capable of releasing hypochlorous acid (HOCl) [84]. However, several studies have indicated the importance of oxidative stress in the development of heart diseases, including MI, $\mathrm{CH}$, and HF. Many clinical studies have revealed that MDA levels are increased in the plasma of patients with chronic HF [85, 86].

In LV remodeling, mitochondrial and cytosolic oxidative stress are important, although NADPH oxidases are crucial for the activation of MMPs [87]. $\mathrm{CH}$ is also observed in diabetes, and one study indicated that protein kinase $\mathrm{C}$ beta is the major moderator of oxidative stress in the diabetic heart, which stimulates NOX [88]. One mouse model of LV hypertrophy induced by Ang II and atrial natriuretic peptide (ANF) indicated the detrimental role of NOX2 activity in Ang II-induced hypertrophy [89].

CRS oxidative stress may occur due to ischemic injury, venous congestion, and inflammation [90]. A human study of CRS type 1 evaluated the contribution of oxidative stress in 11 patients who developed AKI due to acute HF, showing a remarkable increase in ROS and RNS in the circulation [91]. Our previous study characterized oxidative stress in CRS type 3 by induction of renal IRI in mice. Eight days after kidney injury induction, lipid oxidation and increased NO levels in the heart were observed [92]. In contrast, at the same time point in the left kidney, catalase (CAT) activity decreased, but SOD activity increased [92]. Taken together, it is possible to use the evidence of oxidative stress and redox balance in CRS to approach new therapies and improve the clinical conditions observed in CRS patients.

\section{The setback along the highway: emerging mechanisms in CRS}

\section{Uremic toxins in CRS}

To unveil possible new interactions and causes of CRS, studies on the accumulation of UTs and endocrine dysregulation (as mineral bone disorder (MBD)) have been one of the main non-traditional mechanisms of CRS development. The proposed analogy for this review is that the accumulation of UTs can be considered as accidents on highways that lead to traffic on long roads.

UTs are defined as molecules that are incapable of being filtered that accumulate in the bloodstream, causing severe problems to the body's systems, especially the cardiovascular system. The toxicity caused by the accumulation of these molecules lead to the loss of considerable biological functions, and as dilapidation progressed, the uremic retention became more grave due to increasing loss of kidney function (reducing the glomerular filtration rate, GFR) [93-95]. The accumulation of UTs occurs in all types of CRS, especially types 3 and 4, which have a primary renal injury. Renal impairment contributes to gradual structural damage, leading directly to a reduction in GFR and/or subsequent proteinuria [96]. The most notable molecules in the class of water-soluble compounds that play an important role in CRS are urea, creatinine, uric acid, and inorganic phosphorus. The renal injury markers creatinine and urea are related to cardiomyocyte contractile injury and lead to an increase in cardiac oxygen consumption by lowering norepinephrine and causing insulin resistance [97]. Uric acid is also correlated with atrial fibrillation, HF, and hypertension [98]. Furthermore, uric acid was previously associated with negative cardiovascular effects, such as endothelial dysfunction, increased RAAS activity, inflammation, and oxidative stress [99]. Some studies have even linked the progression of CKD in type 2 diabetes and hypertension to high levels of uric acid. Inorganic phosphorus is responsible for the progression of CVD and renal dysfunction. Studies of patients with CKD have associated hyperphosphatemia with a substantially higher incidence of mortality from CVD and peripheral and visceral vascular calcification [100, 101]. The relationship between Pi and cardiovascular diseases, such as coronary disease, ventricular hypertrophy, and HF, increases the mortality rate, ranking these UTs with the largest toxic effect on the cardiovascular system [11, 102, 103]. Pi has been identified in several studies as a UT that causes cardiovascular calcification [56].

High levels of medium toxins, such as fibroblast growth factor 23 (FGF23) and parathyroid hormone (PTH), contribute to progressive renal injury, substantially intervening in the continuous diminishment of GFR and cardiac function. It is important to highlight that these toxins are naturally synthesized by the organism and are crucial for preserving mineral balance. It was observed that after the decline of GFR in patients with CKD stage 5, FGF23 levels increased 1000-fold above normal [104]. FGF23 elevation also impairs the heart tissue in a kidney-independent mechanism, as cardiomyocytes treated with FGF23 develop CH [105] and dysfunctional contraction [106].

The most studied protein-bound (PB) UTs during CRS are indoxyl sulfate (IS) and p-cresyl sulfate (PCS). They cause the direct loss of renal function [45] and increase the mortality of HF patients [107], which are associated with CKD progression. Inflammation has already been studied as one of the factors responsible for the retention of these substances, as well as oxidative stress [108]. Increased levels of 
these toxins are observed in patients with chronic inflammation through the examination of pro-inflammatory cytokines, such as IL-6, TNF- $\alpha$, and IL- $1 \beta$, which lead to LV hypertrophy, cardiac fibrosis, and dysfunction [109]. The ROS release (as $\mathrm{H}_{2} \mathrm{O}_{2}$ and nitrite) from the accumulation of $\mathrm{PB}$ UTs directly induces cardiac injury, with urinary IS excretion reported as having a positive linear correlation with oxidative stress in the heart [108].

The consequences of UT accumulation in blood vessels are always present in renal failure and greatly affect vascular function. As reported by Brunet et al. uremia induces vascular dysfunction mainly due to four aspects: (1) acceleration of atherosclerosis, (2) arterial stiffness, (3) vascular calcification, and (4) intimal hyperplasia [110]. UTs are involved in all these aspects, and their action is closely associated with cardiovascular mortality. Importantly, the overload of PB UTs generated from renal impairment has been associated with a non-traditional risk factors for renal, cardiac, and vascular dysfunction due to distinguished albumin-binding properties, making these solutes non-dialysable under the state of irreversible renal dysfunction [24]. In the vasculature, PB UTs have a range of effects on vascular smooth muscle cells, ECs, immune cells, and erythrocytes. In this way, IS, which is one of the main UTs studied and of a higher concentration compared to other UTs, increases the proliferation, oxidative stress, inflammation, and senescence of vascular smooth muscle cells (VSMCs). Additionally, it increases oxidative stress (observed as $\mathrm{H}_{2} \mathrm{O}_{2}$ and reactive nitrogen isoforms), apoptosis (p53, p21, and p16 proteins), and inflammation, and decreases cell-cell contact of ECs [111]. The mechanisms underlying the effects of PB UTs on the vasculature are the most distinct; however, the imbalance of ROS and inflammation seems to be most prevalent [111].

\section{Epigenetic in CRS}

Emerging data indicates that epigenetic modifications occur due to CKD and CVD development. Among them, smoking, mitochondrial dysfunction, hypertension, and nephron numbers are significantly influenced by in utero environment programming [112]. Many of these modifications are directly involved in setting the five types of CRS; however, the role of histone modification, methylation, and RNA interference directly affecting CRS is unclear. There are new findings concerning cardiorenal physiopathology. Histone $\mathrm{H} 3$ epigenetics undergo strong acetylation, dimethylation, and phosphorylation during renal injury [113]. Induction of cardiomyopathy-related genes is modulated by $\mathrm{H} 3$ modifications [113]. Phosphorylation of $\mathrm{H} 3$ histone was already observed to be controlled by $\mathrm{Ca}_{2}+$ calmodulin-dependent protein kinase II (CAMKII) $\delta$, suggesting that $\mathrm{H} 3$ is related to cardiomyocyte hypertrophy [114]. Once DNA methylation of renal cells is affected by uremia, and this can be a consequence of CRS, the epigenetic implications involving the syndrome have been suggested [115].

Non-coding RNAs, such as short microRNAs, are also part of the epigenetic environment once they work via epigenetic mechanisms. MicroRNAs (miRNAs) can be secreted from cells and reflect the interaction of long-distance organs [116], making them powerful biomarkers of HF or kidney injury, and consequently, CRS. A significant part of these miRNAs are released in the form of extracellular vesicles (EVs). They serve as a "witness" of this crossing on the long road, and every EV has specific membrane proteins from the sender cell, for example, the kidney podocytes $[117,118]$. Intriguingly, some EVs containing miRNA have been found in the plasma of dialysis patients (chronic kidney patients or ESKD) [119, 120]. The literature contains more than 2500 microRNAs that have been isolated or inhibited in some way in experimental models. Here, we report the main discoveries related to microRNAs in CRS, specifically.

The most relevant and studied miRNA in CRS is miR-21, which has been reported in all five CRS types. It is overexpressed in the heart and kidneys after injury and leads to the progression from acute to chronic primary organ dysfunction in CRS [121]. Some studies have shown the cardioprotective and renoprotective roles of miR-21 inhibition during MI, AKI, and diabetes [121]. In the heart, MiR-21 works by enhancing extracellular signal-regulated kinase (ERK)mitogen-activated protein kinase (MAPK) activity, leading to fibrosis and remodeling after cardiomyocyte injury [122]. In the kidneys, miR-21 contributes to the progression of AKI to CKD and is activated by inflammation, apoptosis of EC, and fibrosis [123]. During renal inflammation, IL-6 and extracellular vesicles secreted by macrophages induce miR-21 in renal fibroblasts [122]. MiR-21 can interact with other miRNAs, such as miR-29b, which acts in myocardial fibrosis during infarction after treatment with IS in a CRS model. Rana et al. demonstrated that the elevation of serum concentrations of IS were associated with an increase in miR-21 and a reduction in miR-29b [124]. MiR-21 is also related to the proliferation of tubular epithelial cells, where the knockdown of this miRNA promotes apoptosis of these cells after renal IRI [125].

In the heart, miRNAs are involved in basic mechanisms, including hypertrophy, contraction, and fibrosis [126]. In the blood of patients with HF, miR-423-5, miR320a, miR22, and miR92b were observed, which were related to the severity of CVD [127-130]. MiR-29 is highly expressed in cardiomyocytes after injury and is related to myocardial fibrosis through alterations in TGF- $\beta$ mRNA expression [130]. CH is another phenomenon that appears to be controlled by miRNAs. The roles of miR23a, miR1, miR133, miR199b, and miR208 have been observed [131]. Alterations in miR21, miR199a, miR210, and miR494 were observed after injury, 
associated with cardiomyocyte survival after injury [131], and can be involved in the progression of CRS.

In contrast, in renal tissue, miRNAs are involved in the proliferation and migration of renal tubule cells [132]. In a model of diabetes, MiR-192 is responsible for regulating TGF- $\beta$ in proximal tubule cells by reducing the GFR [133]. Knockdown of the miR-30 family is key to vascular damage and fibrosis in renal cells after injury and is decreased in podocytes of AKI patients [134]. Renal IRI alters the expression of many miRNAs, including miR-687, miR-489, miR494, miR-24, miR-21, and miR-126 [135].

\section{Maintenance of the highway and vehicles: theranostic approaches}

CRS treatments and therapies focus on symptom management through pharmacological methods (Table 2). Pharmacological treatments are mainly aimed at decongestion. Considering that many CRS patients present with congestion, decongestive measures are essential to revert the increased volume overload. The main mechanism proposed to relieve congestion is diuretic use [136].

Type 1 and 2 CRS patients with diuretic resistance, as acute decompensated heart failure (ADHF) and HF, have imbalances in the hemodynamics and activate many mechanisms, which can prolong the time to maximize the concentration of drugs. Additionally, as most diuretics are proteinbound, the volume of distribution increases, reducing diuretic availability [137]. Consequently, CRS types 1 and 2 require higher doses of diuretics than others [138]. Diuretics decrease circulation fluid volume, enhance electrolyte imbalances, and disturb the neurohormonal balance [138]. About $90 \%$ of $\mathrm{HF}$

Table 2 The main management strategies used in each type of cardiorenal syndrome. RAAS, renin-angiotensin-aldosterone system; CKD, chronic kidney disease; MBD, mineral bone disorder; PTH, parathyroid hormone

\begin{tabular}{|c|c|}
\hline CRS & Management strategies \\
\hline 1 & $\begin{array}{l}\text { Congestive relives: vasodilators and diuretics } \\
\text { RAAS blockers } \\
\text { Inotropics }\end{array}$ \\
\hline 2 & $\begin{array}{l}\text { RAAS blockers } \\
\text { Beta-blockers } \\
\text { Erythropoiesis-stimulator agents }\end{array}$ \\
\hline 3 & $\begin{array}{l}\text { Congestive relives: vasodilators and diuretics } \\
\text { Isotonic fluids } \\
\text { Anti-inflammatory drugs }\end{array}$ \\
\hline 4 & $\begin{array}{l}\text { Hemodialysis } \\
\text { Management of CKD-MBD: vitamin D } \\
\text { therapies, PTH inhibitors (cinacalcet), } \\
\text { phosphate binders }\end{array}$ \\
\hline 5 & $\begin{array}{l}\text { Management of the primary disease } \\
\text { Norepirephrine (sepsis), dopamine, vasopressin }\end{array}$ \\
\hline
\end{tabular}

patients take diuretics to prevent short-term mortality and rehospitalization in CRS cases [139].

Inotropics are solutions that are used to treat hypotension and low cardiac output in patients with CRS [140]. The use of dopamine, dobutamine, and milrinone have improved the cardiac index, as well as renal blood flow, easing patient congestion, and improving the mortality rate during CRS, especially for types 1 and 2 [141]. The combination of both dopamine (at low doses) and diuretics seems to be the answer to short-term/acute CRS (types 1 and 3).

Vasodilators can also be used to decongest the central venous pressure as they decrease ventricular filling pressure and myocardial oxygen consumption [142]. Many vasodilators have shown significant results in CRS. The most studied are nesiritide, nitroglycerine, and sodium nitroprusside. They have been shown to be a renal-protective therapy in patients with ADHF [143, 144]. Despite their benefits, these drugs have not been associated with the prevention of CRS, being more effective when used for short-term treatments and conjugated to diuretics [144].

The drugs most commonly used to treat CRS are $\beta$-AR blockers and RAAS inhibitors. $\beta$-AR blockers have been shown to promote an improvement in flow, alleviating BP, and renoprotection, resulting in decreased hospitalization and mortality due to CRS [139]. They block epinephrine and are not recommended for the treatment of type 1 CRS, as they are potentially hypotensive and bradycardic drugs [141]. Interrupting the SNS response is fundamental for the treatment of CRS. The most indicated $\beta$-blockers are propranolol, metoprolol, bisoprolol, and nebivolol in patients with HF, and carvedilol in patients with end-stage renal disease [139].

The process of binding to $\beta$-ARs is a common mechanism shared by all $\beta$-blockers, which compete with agonists for the binding site at the receptor. $\beta$-Blockers activate the coupling of Gi-proteins, inhibiting AC activation. The G $\beta \gamma$ subunit of Gi induces both the inhibition of apoptosis (via stimulation of MAPK and the AKT pathway) and prevents Gs-mediated deleterious effects, leading to cardioprotection. In HF, $\beta$-blockers might lead to cardioprotection and a reduction in cardiac remodeling via NOS activation, which in turn controls the heart rate [145].

RAAS inhibitors are considered the first pharmacological HF therapy and have been extended to the treatment of kidney and cardiorenal diseases, showing efficiency when controlling CRS. In patients with CRS, outstanding activation of AT1 receptors by Ang II contributes to the enhancement of aldosterone from the adrenal glands. Aldosterone promotes water and sodium retention in nephron cells, resulting in increased BP [146]. The RAAS is targeted at different locations during CRS therapies, mostly to control hypertension. RAAS therapies can be divided into angiotensin-converting enzyme inhibitors (ACEIs), ARBs, and direct renin inhibitors (DRIs). 
ACEIs inhibit the conversion of Ang I to Ang II and reduce Ang II in the bloodstream. There is a class of ACEIs, selenium analogs, pharmacologically developed and studied to have an ACE inhibitory effect and to prevent the oxidative stress product, peroxynitrite. The most commonly used ACEI is captopril [147]. ARBs prevent Ang II binding to the AT1 receptor. Studies on the blockade of RAAS with ARBs show a reduction of inflammation and improvement of endothelial function in heart injury and CRS models. Both ACEIs and ARBs display a feedback loop that increases the plasma renin activity (PRA). This happens after the drop-in stimulus to AT1 receptors in the kidney, leading to a compensatory increase in renin release [147].

Finally, DRI use the mechanism of reducing PRA, and the production of Ang I also decreases, leaving less substrate for Ang II conversion by ACE. Furthermore, functional renin is very important to Ang II production and cellular responses to renin. The rapid activation of MAPKs, caused by the binding of renin, triggers intracellular signals responsible for cell survival, gene expression, mitosis, differentiation, and apoptosis [147]. The use of RAAS blockers improves the survival rates in HF patients, while decreasing renal injury and creatinine levels; however, it can cause hyperkalemia. This shows the cardio and renal protection; however, at first use and low doses, the RAAS blockers can decline the GFR once it constricts the arteries, causing what the authors call, the transient and reversible worsening of renal function [148]. This is the reason for the contraindication of RAAS blockers with nonsteroidal anti-inflammatory drugs, as indicated only after addressing volume depletion [148]. Despite being the subject of studies for decades, RAAS blockers are still the target of biotechnological improvements to mitigate the adverse effects observed in chronic treatments.

Concerning CRS caused by the accumulation of UTs, high-flux membranes were created to clear medium molecules; however, the elimination was not efficient in molecules with a molecular mass $>15 \mathrm{kDa}$, such as FGF23 (32 kDa), IL-6 (25 kDa), and myoglobulin (17 kDa) [149, 150]. Sevinc et al. compared patients undergoing high-flux hemodialysis followed by medium-cut-off (MCO) membrane hemodialysis or vice versa. The authors demonstrated that the levels of middle compounds, such as $\beta 2$-microglobulin and myoglobulin, were decreased in the first and last sessions with MCO dialyzers compared to high-flux dialyzers, indicating that it is a possible way to reduce UT levels. Moreover, MCO membrane was capable of significantly reducing serum albumin levels over 3 months of usage [151].

\section{General conclusions}

The purpose of this review was to contribute to the detailing of the main aspects involved in the crosstalk between the kidneys and heart. Only in the 2000s was CRS systematically described and characterized, contributing to the advances observed in the diagnosis and treatment currently present. However, the molecular and cellular mechanisms involved in the different types of CRS are not yet fully understood. Thus, medicine 4.0 has been seeking new tools and strategies to combat different pathologies, and therefore, the understanding of all agents involved in the kidney-heart connection remains urgent.

Funding The authors received financial support from the São Paulo Research Foundation (FAPESP) grants 2008/10175-4, 2015/19107-5, 2018/03089-6, and 2019/11077-0.

\section{Declarations}

Conflict of interest The authors declare no competing interests.

\section{References}

1. Bright $\mathrm{R}$ (1836) Cases and observations illustrative of renal disease, accompanied with the secretion of albuminous urine. Medico-chirurgical Rev 25:23-35

2. Hatamizadeh P, Fonarow GC, Budoff MJ et al (2013) Cardiorenal syndrome: pathophysiology and potential targets for clinical management. Nat Rev Nephrol 9:99-111. https://doi.org/10. 1038/nrneph.2012.279

3. Ronco C, McCullough P, Anker SD et al (2010) Cardio-renal syndromes: report from the consensus conference of the Acute Dialysis Quality Initiative. Eur Heart J 31:703-711. https://doi. org/10.1093/eurheartj/ehp507

4. Savira F, Magaye R, Liew D et al (2020) Cardiorenal syndrome: multi-organ dysfunction involving the heart, kidney and vasculature. Br J Pharmacol 177:2906-2922. https://doi.org/10.1111/ bph. 15065

5. Doi K, Noiri E (2016) Mitochondrial dysfunction in cardiorenal syndrome. Antioxidants Redox Signal 25:200-207. https://doi. org/10.1089/ars.2016.6654

6. Raina R, Nair N, Chakraborty R et al (2020) An update on the pathophysiology and treatment of cardiorenal syndrome. Cardiol Res 11:76-88. https://doi.org/10.14740/cr955

7. Di Lullo L, Bellasi A, Barbera V et al (2017) Pathophysiology of the cardio-renal syndromes types 1-5: An uptodate. Indian Heart J 69:255-265. https://doi.org/10.1016/j.ihj.2017.01.005

8. Clementi A, Virzì GM, Battaglia GG, Ronco C (2019) Neurohormonal, endocrine, and immune dysregulation and inflammation in cardiorenal syndrome. Cardiorenal Med 9:265-273. https:// doi.org/10.1159/000500715

9. Di Lullo L, House A, Gorini A et al (2015) Chronic kidney disease and cardiovascular complications. Heart Fail Rev 20:259272. https://doi.org/10.1007/s10741-014-9460-9

10. Navarro-García JA, Fernández-Velasco M, Delgado C et al (2018) PTH, vitamin D, and the FGF-23-klotho axis and heart: Going beyond the confines of nephrology. Eur J Clin Invest 48

11. Falconi CA, Junho CVC, Fogaça-Ruiz F et al (2021) Uremic toxins: an alarming danger concerning the cardiovascular system. Front Physiol 12. https://doi.org/10.3389/fphys.2021.686249

12. Colombo PC, Ganda A, Lin J et al (2012) Inflammatory activation: Cardiac, renal, and cardio-renal interactions in patients with 
the cardiorenal syndrome. Heart Fail Rev 17:177-190. https:// doi.org/10.1007/s10741-011-9261-3

13. Mehta RL, Bouchard J, Soroko SB et al (2011) Sepsis as a cause and consequence of acute kidney injury: program to improve care in acute renal disease. Intensive Care Med 37:241-248. https:// doi.org/10.1007/s00134-010-2089-9

14. Ronco C, Di Lullo L (2014) Cardiorenal syndrome Heart Fail Clin 10:251-280

15. Adams PL, Adams FF, Bell PD, Navar LG (1980) Impaired renal blood flow autoregulation in ischemic acute renal failure. Kidney Int 18:68-76. https://doi.org/10.1038/ki.1980.111

16. Matthys E, Patton MK, Osgood RW et al (1983) Alterations in vascular function and morphology in acute ischemic renal failure. Kidney Int 23:717-724. https://doi.org/10.1038/ki.1983.84

17. Conger JD, Robinette JB, Hammond WS (1991) Differences in vascular reactivity in models of ischemic acute renal failure. Kidney Int 39:1087-1097. https://doi.org/10.1038/ki.1991.138

18. Yang C-C, Chen Y-T, Chen C-H et al (2019) The therapeutic impact of entresto on protecting against cardiorenal syndromeassociated renal damage in rats on high protein diet. Biomed Pharmacother 116:108954. https://doi.org/10.1016/j.biopha. 2019.108954

19. Mohammadi M, Najafi H, Mohamadi Yarijani Z et al (2020) Protective effect of piperine in ischemia-reperfusion induced acute kidney injury through inhibition of inflammation and oxidative stress. J Tradit Complement Med 10:570-576. https://doi.org/10. 1016/j.jtcme.2019.07.002

20. Casas A, Mallén A, Blasco-Lucas A et al (2020) Chronic kidney disease-associated inflammation increases the risks of acute kidney injury and mortality after cardiac surgery. Int J Mol Sci 21:9689. https://doi.org/10.3390/ijms21249689

21. Ueda S, Ayano Y, Yano S et al (1981) Changes in vascular reactivity in rats with experimental renal insufficiency. Arch Int Pharmacodyn Ther 253:257-265

22. Amann K (1995) Changes of vascular architecture independent of blood pressure in experimental uremia. Am J Hypertens 8:409-417. https://doi.org/10.1016/0895-7061(94)00248-A

23. Nesher N, Frolkis I, Schwartz D et al (2014) L-arginine improves endothelial function, independently of arginine uptake, in aortas from chronic renal failure female rats. Am J Physiol Physiol 306:F449-F456. https://doi.org/10.1152/ajprenal.00457.2013

24. Yamamoto K, Chappell MC, Brosnihan KB, Ferrario CM (1992) In vivo metabolism of angiotensin I by neutral endopeptidase (EC 3.4.24.11) in spontaneously hypertensive rats. Hypertension 19:692-696. https://doi.org/10.1161/01.HYP.19.6.692

25. Dzau VJ, Colucci WS, Williams GH et al (1980) Sustained effectiveness of converting-enzyme inhibition in patients with severe congestive heart failure. N Engl J Med 302:1373-1379. https:// doi.org/10.1056/NEJM198006193022501

26. Turini G, Brunner H, Gribic M et al (1979) Improvement of chronic congestive heart-failure by oral captopril. Lancet 313:1213-1215. https://doi.org/10.1016/S0140-6736(79)91897-X

27. Nio Y, Matsubara H, Murasawa S et al (1995) Regulation of gene transcription of angiotensin II receptor subtypes in myocardial infarction. J Clin Invest 95:46-54. https://doi.org/10.1172/JCI117675

28. Zhu Y-C, Zhu Y-Z, Gohlke P et al (1997) Effects of angiotensinconverting enzyme inhibition and angiotensin II AT1 receptor antagonism on cardiac parameters in left ventricular hypertrophy. Am J Cardiol 80:110A-117A. https://doi.org/10.1016/S00029149(97)00465-7

29. Wu J, You J, Wang S et al (2014) Insights into the activation and inhibition of angiotensin II type 1 receptor in the mechanically loaded heart. Circ J 78:1283-1289. https://doi.org/10.1253/circj. CJ-14-0470

30. Carneiro-Ramos MS, Diniz GP, Nadu AP et al (2010) Blockage of angiotensin II type 2 receptor prevents thyroxine-mediated cardiac hypertrophy by blocking Akt activation. Basic Res Cardiol 105:325-335. https://doi.org/10.1007/s00395-010-0089-0

31. Diniz GP, Carneiro-Ramos MS, Barreto-Chaves MLM (2009) Angiotensin type 1 receptor mediates thyroid hormone-induced cardiomyocyte hypertrophy through the Akt/GSK-3 $\beta / \mathrm{mTOR}$ signaling pathway. Basic Res Cardiol 104:653-667. https://doi. org/10.1007/s00395-009-0043-1

32. Vignier N, Le Corvoisier P, Blard C et al (2014) AT1 blockade abolishes left ventricular hypertrophy in heterozygous cMyBP-C null mice: role of FHL1. Fundam Clin Pharmacol 28:249-256. https://doi.org/10.1111/fcp.12031

33. Weber KT (2001) Aldosterone in congestive heart failure. N Engl J Med 345:1689-1697. https://doi.org/10.1056/NEJMra000050

34. Dai W, Kloner RA (2011) Potential role of renin-angiotensin system blockade for preventing myocardial ischemia/reperfusion injury and remodeling after myocardial infarction. Postgrad Med 123:49-55. https://doi.org/10.3810/pgm.2011.03.2263

35. Panico K, Abrahão MV, Trentin-Sonoda M et al (2019) Cardiac inflammation after ischemia-reperfusion of the kidney: Role of the sympathetic nervous system and the renin-angiotensin system. Cell Physiol Biochem 53:587-605. https://doi.org/10.33594/ 000000159

36. Zhong J, Guo D, Chen CB et al (2011) Prevention of angiotensin II-mediated renal oxidative stress, inflammation, and fibrosis by angiotensin-converting enzyme 2. Hypertension 57:314-322. https://doi.org/10.1161/HYPERTENSIONAHA.110.164244

37. Zhuo JL, Li XC (2011) New insights and perspectives on intrarenal renin-angiotensin system: focus on intracrine/intracellular angiotensin II. Peptides 32:1551-1565. https://doi.org/10.1016/j. peptides.2011.05.012

38. Santos RAS, Oudit GY, Verano-Braga T et al (2019) The reninangiotensin system: going beyond the classical paradigms. Am J Physiol Circ Physiol 316:H958-H970. https://doi.org/10.1152/ ajpheart.00723.2018

39. Patel VB, Zhong J-C, Grant MB, Oudit GY (2016) Role of the ACE2/angiotensin 1-7 axis of the renin-angiotensin system in heart failure. Circ Res 118:1313-1326. https://doi.org/10.1161/ CIRCRESAHA.116.307708

40. Amraei R, Rahimi N (2020) COVID-19, renin-angiotensin system and endothelial dysfunction. Cells 9:1652. https://doi.org/ 10.3390/cells9071652

41. Pecly IMD, Azevedo RB, Muxfeldt ES et al (2021) A review of Covid-19 and acute kidney injury: from pathophysiology to clinical results. Brazilian J Nephrol. https://doi.org/10.1590/ 2175-8239-jbn-2020-0204

42. Carter JR, Goldstein DS (2014) Sympathoneural and adrenomedullary responses to mental stress. Comprehensive physiology. John Wiley \& Sons Inc, Hoboken, NJ, USA, pp 119-146

43. Burnstock G (2013) Cotransmission in the autonomic nervous system. Handbook Clin Neurol 23-35

44. Park J (2012) Cardiovascular risk in chronic kidney disease: role of the sympathetic nervous system. Cardiol Res Pract 2012:1-8. https://doi.org/10.1155/2012/319432

45. Trentin-Sonoda M, Da Silva RC, Kmit FV et al (2015) Knockout of toll-like receptors 2 and 4 prevents renal ischemia-reperfusioninduced cardiac hypertrophy in mice. PLoS ONE 10:1-21. https:// doi.org/10.1371/journal.pone.0139350

46. Alarcon MML, Trentin-Sonoda M, Panico K et al (2019) Cardiac arrhythmias after renal I/R depend on IL-1 $\beta$. J Mol Cell Cardiol 131:101-111. https://doi.org/10.1016/j.yjmcc.2019.04.025

47. Veiga AC, Milanez MIO, Campos RR et al (2021) The involvement of renal afferents in the maintenance of cardiorenal diseases. Am J Physiol Integr Comp Physiol 320:R88-R93. https:// doi.org/10.1152/ajpregu.00225.2020

48. Ramchandra R, Xing DT, Matear M et al (2019) Neurohumoral interactions contributing to renal vasoconstriction and decreased 
renal blood flow in heart failure. Am J Physiol Integr Comp Physiol 317:R386-R396. https://doi.org/10.1152/ajpregu.00026.2019

49. Fujiu K, Shibata M, Nakayama Y et al (2017) A heart-brain-kidney network controls adaptation to cardiac stress through tissue macrophage activation. Nat Med 23:611-622. https://doi.org/10.1038/nm.4326

50. Jougasaki M, Tachibana I, Luchner A et al (2000) Augmented cardiac cardiotrophin-1 in experimental congestive heart failure. Circulation 101:14-17. https://doi.org/10.1161/01.CIR.101.1.14

51. Elenkov IJ, Wilder RL, Chrousos GP, Vizi ES (2000) The sympathetic nerve-an integrative interface between two supersystems: the brain and the immune system. Pharmacol Rev 52:595-638

52. Crowley SD, Gurley SB, Herrera MJ et al (2006) Angiotensin II causes hypertension and cardiac hypertrophy through its receptors in the kidney. Proc Natl Acad Sci 103:17985-17990. https:// doi.org/10.1073/pnas.0605545103

53. Stupin A, Drenjancevic I, Rasic L et al (2017) A cross-talk between the renin-angiotensin and adrenergic systems in cardiovascular health and disease. Eur Med J 1:90-107

54. Chaar LJ, Alves TP, Batista Junior AM, Michelini LC (2015) Early training-induced reduction of angiotensinogen in autonomic areas-the main effect of exercise on brain renin-angiotensin system in hypertensive rats. PLoS ONE 10:e0137395. https://doi.org/ 10.1371/journal.pone.0137395

55. Gueguen C, Jackson KL, Marques FZ et al (2019) Renal nerves contribute to hypertension in Schlager BPH/2J mice. Hypertens Res 42:306-318. https://doi.org/10.1038/s41440-018-0147-9

56. Vieira-Rocha MS, Rodríguez-Rodríguez P, Sousa JB et al (2019) Vascular angiotensin AT1 receptor neuromodulation in fetal programming of hypertension. Vascul Pharmacol 117:27-34. https:// doi.org/10.1016/j.vph.2018.10.003

57. Chen B, Frangogiannis NG (2017) Immune cells in repair of the infarcted myocardium. Microcirculation 24:e12305. https://doi. org/10.1111/micc.12305

58. Clementi A, Virzì GM, Brocca A et al (2015) Advances in the pathogenesis of cardiorenal syndrome type 3. Oxid Med Cell Longev 2015:1-8. https://doi.org/10.1155/2015/148082

59. Ayoub KF, Pothineni NVK, Rutland J et al (2017) Immunity, inflammation, and oxidative stress in heart failure: emerging molecular targets. Cardiovasc Drugs Ther 31:593-608. https:// doi.org/10.1007/s10557-017-6752-z

60. Jo E-K, Kim JK, Shin D-M, Sasakawa C (2016) Molecular mechanisms regulating NLRP3 inflammasome activation. Cell Mol Immunol 13:148-159. https://doi.org/10.1038/cmi.2015.95

61. Monnerat G, Alarcón ML, Vasconcellos LR et al (2016) Macrophagedependent IL-1 $\beta$ production induces cardiac arrhythmias in diabetic mice. Nat Commun 7:13344. https://doi.org/10.1038/ncomms13344

62. Pullen AB, Jadapalli JK, Rhourri-Frih B, Halade GV (2020) Re-evaluating the causes and consequences of non-resolving inflammation in chronic cardiovascular disease. Heart Fail Rev 25:381-391. https://doi.org/10.1007/s10741-019-09817-x

63. Carrillo-Salinas FJ, Ngwenyama N, Anastasiou M et al (2019) Heart inflammation. Am J Pathol 189:1482-1494. https://doi. org/10.1016/j.ajpath.2019.04.009

64. Adamo L, Rocha-Resende C, Prabhu SD, Mann DL (2020) Reappraising the role of inflammation in heart failure. Nat Rev Cardiol 17:269-285. https://doi.org/10.1038/s41569-019-0315-x

65. Patel B, Ismahil MA, Hamid T et al (2017) Mononuclear phagocytes are dispensable for cardiac remodeling in established pressureoverload heart failure. PLoS ONE 12:e0170781. https://doi.org/ 10.1371/journal.pone.0170781

66. Schiattarella GG, Sequeira V, Ameri P (2020) Distinctive patterns of inflammation across the heart failure syndrome. Heart Fail Rev. https://doi.org/10.1007/s10741-020-09949-5

67. Virzì GM, Zhang J, Nalesso F et al (2018) The role of dendritic and endothelial cells in cardiorenal syndrome. Cardiorenal Med 8:92-104. https://doi.org/10.1159/000485937
68. Ronco C, Di Lullo L (2018) Cardiorenal acute kidney injury: epidemiology, presentation, causes, pathophysiology, and treatment. core concepts in acute kidney injury. Springer, US, New York, NY, pp 257-269

69. Castillo-Rodríguez E, Pizarro-Sánchez S, Sanz AB et al (2017) Inflammatory cytokines as uremic toxins: "ni son todos los queestan, ni estan todos los que son" Toxins (Basel) 9. https:// doi.org/10.3390/toxins9040114

70. Junho CVC, Azevedo CAB, da Cunha RS et al (2021) Heat shock proteins: connectors between heart and kidney. Cells 10:1939. https://doi.org/10.3390/cells10081939

71. Ortega-Hernández J, Springall R, Sánchez-Muñoz F et al (2017) Acute coronary syndrome and acute kidney injury: role of inflammation in worsening renal function. BMC Cardiovasc Disord 17:202. https://doi.org/10.1186/s12872-017-0640-0

72. Machado Rocha Ribeiro S, Humberto de Queiroz J, do Carmo Gouveia Peluzio M et al (2005) The formation and the effects of the reactive oxygen species in biological media. Biosci $\mathrm{J}$ 21:133-149

73. Pruchniak MP, Araźna M, Demkc U (2016) Biochemistry of oxidative stress. Advances in experimental medicine and biology. Springer, New York LLC, pp 9-19

74. Siti HN, Kamisah Y, Kamsiah J (2015) The role of oxidative stress, antioxidants and vascular inflammation in cardiovascular disease (a review). Vascul Pharmacol 71:40-56

75. Duann P, Lin PH (2017) Mitochondria damage and kidney disease. Advances in experimental medicine and biology. Springer, New York LLC, pp 529-551

76. Ratliff BB, Abdulmahdi W, Pawar R, Wolin MS (2016) Oxidant mechanisms in renal injury and disease. Antioxidants Redox Signal 25:119-146

77. Thomas SR, Witting PK, Drummond GR (2008) Redox control of endothelial function and dysfunction: molecular mechanisms and therapeutic opportunities. Antioxidants Redox Signal 10:1713-1765

78. Aydinoz S, Uzun G, Cermik H et al (2007) Effects of different doses of hyperbaric oxygen on cisplatin-induced nephrotoxicity. Ren Fail 29:257-263. https://doi.org/10.1080/08860220601166487

79. Jha JC, Banal C, Chow BSM et al (2016) Diabetes and kidney disease: role of oxidative stress. Antioxidants Redox Signal 25:657-684

80. Choi EK, Jung H, Kwak KH et al (2017) Inhibition of oxidative stress in renal ischemia-reperfusion injury. Anesth Analg 124:204-213. https://doi.org/10.1213/ANE.0000000000001565

81. Kim HJ, Vaziri ND (2010) Contribution of impaired Nrf2-Keap1 pathway to oxidative stress and inflammation in chronic renal failure. Am J Physiol Ren Physiol 298. https://doi.org/10.1152/ ajprenal.00421.2009

82. Lee DY, Wauquier F, Eid AA et al (2013) Nox4 NADPH oxidase mediates peroxynitrite-dependent uncoupling of endothelial nitric-oxide synthase and fibronectin expression in response to angiotensin II: Role of mitochondrial reactive oxygen species. J Biol Chem 288:28668-28686. https://doi.org/10.1074/jbc.M113. 470971

83. Kang SJ, You A, Kwak MK (2011) Suppression of Nrf2 signaling by angiotensin II in murine renal epithelial cells. Arch Pharm Res 34:829-836. https://doi.org/10.1007/s12272-011-0517-1

84. Rababa'h AM, Guillory AN, Mustafa R, Hijjawi T, (2018) Oxidative stress and cardiac remodeling: an updated edge. Curr Cardiol Rev 14:53-59. https://doi.org/10.2174/1573403x14666180111145207

85. Hamilton CA, Miller WH, Al-Benna S et al (2004) Strategies to reduce oxidative stress in cardiovascular disease. Clin Sci 106:219-234

86. Tsutsui H, Kinugawa S, Matsushima S (2009) Mitochondrial oxidative stress and dysfunction in myocardial remodelling. Cardiovasc Res 81:449-456 
87. Siwik DA, Pagano PJ, Colucci WS (2001) Oxidative stress regulates collagen synthesis and matrix metalloproteinase activity in cardiac fibroblasts. Am J Physiol Cell Physiol 280. https:// doi.org/10.1152/ajpcell.2001.280.1.c53

88. Liu Y, Lei S, Gao X et al (2012) PKC $\beta$ inhibition with ruboxistaurin reduces oxidative stress and attenuates left ventricular hypertrophy and dysfuntion in rats with streptozotocin-induced diabetes. Clin Sci 122:161-173. https://doi.org/10.1042/CS20110176

89. Looi YH, Grieve DJ, Siva A et al (2008) Involvement of Nox2 NADPH oxidase in adverse cardiac remodeling after myocardial infarction. Hypertension 51:319-325. https://doi.org/10. 1161/HYPERTENSIONAHA.107.101980

90. Giam B, Kaye DM, Rajapakse NW (2016) Role of renal oxidative stress in the pathogenesis of the cardiorenal syndrome. Hear Lung Circ 25:874-880

91. Boaz M, Smetana S, Weinstein T et al (2000) Secondary prevention with antioxidants of cardiovascular disease in endstage renal disease (SPACE): Randomised placebo-controlled trial. Lancet 356:1213-1218. https://doi.org/10.1016/S01406736(00)02783-5

92. Caio-Silva W, da Silva DD, Junho CVC et al (2020) Characterization of the oxidative stress in renal ischemia/reperfusion-induced cardiorenal syndrome type 3. Biomed Res Int 2020:1605358. https://doi.org/10.1155/2020/1605358

93. Glassock RJ (2008) Uremic toxins: what are they? An integrated overview of pathobiology and classification. J Ren Nutr 18:2-6. https://doi.org/10.1053/j.jrn.2007.10.003

94. Stinghen AEMEM, Gonçalves SMM, Martines EGG et al (2009) Increased plasma and endothelial cell expression of chemokines and adhesion molecules in chronic kidney disease. Nephron Clin Pract 111:c117-c126. https://doi.org/10.1159/000191205

95. Gryp T, Vanholder R, Vaneechoutte M, Glorieux G (2017) p-Cresyl Sulfate. Toxins (Basel) 9:52. https://doi.org/10.3390/toxins9020052

96. Barreto FC, Stinghen AEM, de Oliveira RB et al (2014) The quest for a better understanding of chronic kidney disease complications: an update on uremic toxins. J Bras Nefrol 36:221235. https://doi.org/10.5935/0101-2800.20140033

97. Lekawanvijit S, Krum H (2015) Cardiorenal syndrome: role of protein-bound uremic toxins. J Ren Nutr 25:149-154. https://doi. org/10.1053/j.jrn.2014.10.009

98. Tamariz L, Hernandez F, Bush A et al (2014) Association between serum uric acid and atrial fibrillation: a systematic review and meta-analysis. Hear Rhythm 11:1102-1108. https:// doi.org/10.1016/j.hrthm.2014.04.003

99. Chaudhary K, Malhotra K, Sowers J, Aroor A (2013) Uric acidkey ingredient in the recipe for cardiorenal metabolic syndrome. CardioRenal Med 3:208-220. https://doi.org/10.1159/000355405

100. Dhingra R, Gona P, Benjamin EJ et al (2010) Relations of serum phosphorus levels to echocardiographic left ventricular mass and incidence of heart failure in the community. Eur J Heart Fail 12:812-818. https://doi.org/10.1093/eurjhf/hfq106

101. Cancela AL, Santos RD, Titan SM et al (2012) Phosphorus is associated with coronary artery disease in patients with preserved renal function. PLoS ONE 7:e36883. https://doi.org/10. 1371/journal.pone.0036883

102. Dhingra $R$ (2007) Relations of serum phosphorus and calcium levels to the incidence of cardiovascular disease in the community. Arch Intern Med 167:879. https://doi.org/10.1001/archinte. 167.9.879

103. Tonelli M, Sacks F, Pfeffer M et al (2005) Relation between serum phosphate level and cardiovascular event rate in people with coronary disease. Circulation 112:2627-2633. https://doi. org/10.1161/CIRCULATIONAHA.105.553198

104. Edmonston D, Wolf M (2020) FGF23 at the crossroads of phosphate, iron economy and erythropoiesis. Nat Rev Nephrol $16: 7-19$
105. Faul C, Amaral AP, Oskouei B et al (2011) FGF23 induces left ventricular hypertrophy. J Clin Invest 121:4393-4408. https:// doi.org/10.1172/JCI46122

106. Navarro-García JA, Delgado C, Fernández-Velasco M et al (2019) Fibroblast growth factor-23 promotes rhythm alterations and contractile dysfunction in adult ventricular cardiomyocytes. Nephrol Dial Transplant 34:1864-1875. https://doi.org/10.1093/ ndt/gfy392

107. Storino GF, Moraes C, Saldanha J, Mafra D (2015) Cardiovascular mortality in chronic kidney patients: the role of uremic toxins. Int J Cardiovasc Sci 28. https://doi.org/10.5935/2359-4802. 20150047

108. Lekawanvijit S (2018) Cardiotoxicity of uremic toxins: a driver of cardiorenal syndrome. Toxins (Basel) 10:352. https://doi.org/ 10.3390/toxins 10090352

109. Huang SY, Chen YA, Chen SA et al (2016) Uremic toxins-novel arrhythmogenic factor in chronic kidney disease-related atrial fibrillation. Acta Cardiol Sin 32:259-264. https://doi.org/10. 6515/ACS20151116A

110. Brunet P, Gondouin B, Duval-Sabatier A et al (2011) Does uremia cause vascular dysfunction? Kidney Blood Press Res 34:284-290. https://doi.org/10.1159/000327131

111. Savira F, Magaye R, Hua Y et al (2019) Molecular mechanisms of protein-bound uremic toxin-mediated cardiac, renal and vascular effects: underpinning intracellular targets for cardiorenal syndrome therapy. Toxicol Lett 308:34-49. https://doi.org/10. 1016/j.toxlet.2019.03.002

112. McCullough PA, Ronco C (2021) Textbook of cardiorenal medicine. Springer International Publishing, Cham

113. Gaikwad AB, Sayyed SG, Lichtnekert J et al (2010) Renal failure increases cardiac histone $\mathrm{H} 3$ acetylation, dimethylation, and phosphorylation and the induction of cardiomyopathy-related genes in type 2 diabetes. Am J Pathol 176:1079-1083. https:// doi.org/10.2353/ajpath.2010.090528

114. Awad S, Al-Haffar KMA, Marashly Q et al (2015) Control of histone $\mathrm{H} 3$ phosphorylation by CaMKII. in response to haemodynamic cardiac stress. J Pathol 235:606-618. https://doi.org/10. 1002/path.4489

115. Beckerman P, Ko YA, Susztak K (2014) Epigenetics: a new way to look at kidney diseases. Nephrol Dial Transplant 29:18211827. https://doi.org/10.1093/ndt/gfu026

116. Bartel DP (2004) MicroRNAs Cell 116:281-297. https://doi.org/ 10.1016/S0092-8674(04)00045-5

117. Borges FT, Reis LA, Schor N (2013) Extracellular vesicles: structure, function, and potential clinical uses in renal diseases. Brazilian J Med Biol Res 46:824-830. https://doi.org/10.1590/ 1414-431X20132964

118. Medeiros T, Myette RL, Almeida JR et al (2020) Extracellular vesicles: cell-derived biomarkers of glomerular and tubular injury. Cell Physiol Biochem 54:88-109. https://doi.org/10. 33594/000000207

119. Salih M, Zietse R, Hoorn EJ (2014) Urinary extracellular vesicles and the kidney: biomarkers and beyond. Am J Physiol Physiol 306:F1251-F1259. https://doi.org/10.1152/ajprenal.00128.2014

120. De S, Kuwahara S, Hosojima M et al (2017) Exocytosis-mediated urinary full-length megalin excretion is linked with the pathogenesis of diabetic nephropathy. Diabetes 66:1391-1404. https:// doi.org/10.2337/db16-1031

121. Huang CK, Bär C, Thum T (2020) miR-21, mediator, and potential therapeutic target in the cardiorenal syndrome. Front Pharmacol 11. https://doi.org/10.3389/fphar.2020.00726

122. Thum T, Gross C, Fiedler J et al (2008) MicroRNA-21 contributes to myocardial disease by stimulating MAP kinase signalling in fibroblasts. Nature 456:980-984. https://doi.org/10.1038/nature07511

123. Hinkel R, Ramanujam D, Kaczmarek V et al (2020) AntimiR-21 prevents myocardial dysfunction in a pig model of ischemia/reperfusion 
injury. J Am Coll Cardiol 75:1788-1800. https://doi.org/10.1016/j. jacc.2020.02.041

124. Rana I, Kompa AR, Skommer J et al (2015) Contribution of microRNA to pathological fibrosis in cardio-renal syndrome: impact of uremic toxins. Physiol Rep 3:e12371. https://doi.org/ $10.14814 /$ phy 2.12371

125. Godwin JG, Ge X, Stephan K et al (2010) Identification of a microRNA signature of renal ischemia reperfusion injury. Proc Natl Acad Sci 107:14339-14344. https://doi.org/10.1073/pnas. 0912701107

126. Eulalio A, Mano M, Ferro MD et al (2012) Functional screening identifies miRNAs inducing cardiac regeneration. Nature 492:376-381. https://doi.org/10.1038/nature11739

127. Corsten MF, Dennert R, Jochems S et al (2010) Circulating MicroRNA-208b and microRNA-499 reflect myocardial damage in cardiovascular disease. Circ Cardiovasc Genet 3:499-506. https://doi.org/10.1161/CIRCGENETICS.110.957415

128. Goren Y, Kushnir M, Zafrir B et al (2012) Serum levels of microRNAs in patients with heart failure. Eur J Heart Fail 14:147-154. https://doi.org/10.1093/eurjhf/hfr155

129. Tijsen AJ, Creemers EE, Moerland PD et al (2010) MiR423-5p as a circulating biomarker for heart failure. Circ Res 106:10351039. https://doi.org/10.1161/CIRCRESAHA.110.218297

130. van Rooij E, Sutherland LB, Thatcher JE et al (2008) Dysregulation of microRNAs after myocardial infarction reveals a role of miR-29 in cardiac fibrosis. Proc Natl Acad Sci 105:1302713032. https://doi.org/10.1073/pnas.0805038105

131. Han M, Toli J, Abdellatif M (2011) MicroRNAs in the cardiovascular system. Curr Opin Cardiol 26:181-189. https://doi.org/ 10.1097/HCO.0b013e328345983d

132. Tian Z, Greene AS, Pietrusz JL et al (2008) MicroRNA-target pairs in the rat kidney identified by microRNA microarray, proteomic, and bioinformatic analysis. Genome Res 18:404-411. https://doi.org/10.1101/gr.6587008

133. Kato M, Zhang J, Wang M et al (2007) MicroRNA-192 in diabetic kidney glomeruli and its function in TGF- $\beta$-induced collagen expression via inhibition of E-box repressors. Proc Natl Acad Sci U S A 104:3432-3437. https://doi.org/10.1073/pnas. 0611192104

134. Wu J, Zheng C, Fan Y et al (2014) Downregulation of MicroRNA-30 facilitates podocyte injury and is prevented by glucocorticoids. J Am Soc Nephrol 25:92-104. https://doi.org/10.1681/ASN.2012111101

135. Liu Z, Wang S, Mi Q-S, Dong Z (2016) MicroRNAs in pathogenesis of acute kidney injury. Nephron 134:149-153. https:// doi.org/10.1159/000446551

136. Rubinstein J, Sanford D (2019) Treatment of cardiorenal syndrome. Cardiol Clin 37:267-273. https://doi.org/10.1016/j.ccl. 2019.04.002

137. Hoorn EJ, Ellison DH (2017) Diuretic resistance. Am J Kidney Dis 69:136-142. https://doi.org/10.1053/j.ajkd.2016.08.027

138. Cohen L (2014) The cardiorenal syndrome: pathophysiologic crosstalk, outcomes, and treatment targets. Cardiovasc Hematol Disord Targets 14:170-176. https://doi.org/10.2174/1871529X14666140701100913
139. Rangaswami J, Bhalla V, Blair JEA et al (2019) Cardiorenal syndrome: classification, pathophysiology, diagnosis, and treatment strategies: a scientific statement from the American Heart Association Circulation 139. https://doi.org/10.1161/CIR.0000000000000664

140. Cowger JA, Radjef R (2018) Advanced heart failure therapies and cardiorenal syndrome. Adv Chronic Kidney Dis 25:443-453. https://doi.org/10.1053/j.ackd.2018.08.012

141. Kim CS (2013) Pharmacologic management of the cardio-renal syndrome. Electrolytes Blood Press 11:17. https://doi.org/10. 5049/EBP.2013.11.1.17

142. Testani JM, Coca SG, McCauley BD et al (2011) Impact of changes in blood pressure during the treatment of acute decompensated heart failure on renal and clinical outcomes. Eur J Heart Fail 13:877-884. https://doi.org/10.1093/eurjhf/hfr070

143. Sackner-Bernstein JD, Skopicki HA, Aaronson KD (2005) Risk of worsening renal function with nesiritide in patients with acutely decompensated heart failure. Circulation 111:1487-1491. https://doi.org/10.1161/01.CIR.0000159340.93220.E4

144. O'Connor CM, Starling RC, Hernandez AF et al (2011) Effect of nesiritide in patients with acute decompensated heart failure. $\mathrm{N}$ Engl J Med 365:32-43. https://doi.org/10.1056/NEJMoa1100171

145. Oliver E, Mayor F Jr, D'Ocon P (2019) Beta-blockers: historical perspective and mechanisms of action. Rev Española Cardiol English Ed 72:853-862. https://doi.org/10.1016/j.rec.2019.04. 006

146. Cagnoni F (2010) Blocking the RAAS at different levels: an update on the use of the direct renin inhibitors alone and in combination. Vasc Health Risk Manag 549. https://doi.org/10.2147/ VHRM.S11816

147. Pacurari M, Kafoury R, Tchounwou PB, Ndebele K (2014) The renin-angiotensin-aldosterone system in vascular inflammation and remodeling. Int J Inflam 2014:1-13. https://doi.org/10.1155/ $2014 / 689360$

148. Takahama H, Kitakaze M (2017) Pathophysiology of cardiorenal syndrome in patients with heart failure: potential therapeutic targets. Am J Physiol Circ Physiol 313:H715-H721. https://doi. org/10.1152/ajpheart.00215.2017

149. Ronco C (2017) The rise of expanded hemodialysis. Blood Purif 44:I-VIII. https://doi.org/10.1159/000476012

150. Wolley MJ, Hutchison CA (2018) Large uremic toxins: an unsolved problem in end-stage kidney disease. Nephrol Dial Transplant 33:iii6-iii11. https://doi.org/10.1093/ndt/gfy179

151. Sevinc M, Hasbal NB, Yilmaz V et al (2020) Comparison of circulating levels of uremic toxins in hemodialysis patients treated with medium cut-off membranes and high-flux membranes: Theranova in Sisli Hamidiye Etfal (THE SHE) Randomized Control Study. Blood Purif 49:733-742. https://doi.org/10.1159/ 000508061

Publisher's Note Springer Nature remains neutral with regard to jurisdictional claims in published maps and institutional affiliations. 